\title{
CONSTITUCIÓN Y PROPIEDAD INTELECTUAL: UN NUEVO MARCO PARA BALANCEAR LA CREACIÓN Y ACCESO AL CONOCIMIENTO
}

\section{CONSTITUTION AND INTELLECTUAL PROPERTY: \\ A NEW FRAMEWORK TO BALANCE THE CREATION AND ACCESS TO KNOWLEDGE}

\author{
Juan Pablo Iglesias Mujica*
}

"To promote the progress of science and useful arts, by securing for limited times to authors and inventors the exclusive right to their respective writings and discoveries" (Art. $1^{\circ}$, sección $8^{\circ}$, de la Constitución de Estados Unidos de Norteamérica)

\section{Resumen}

La norma constitucional actual sobre propiedad intelectual ( $\operatorname{art} .19$ n. $\left.{ }^{\circ} 25\right)$ es deficitaria porque es opaca respecto a los objetivos económicos y sociales de dicha especie de propiedad. Por ello y en atención al crecimiento de la economía de base intangible en el siglo XXI, resulta necesario y oportuno diseñar una nueva norma constitucional que no se remita de forma irreflexiva a la regla general sobre propiedad, de modo de reflejar el carácter instrumental de la propiedad intelectual, en tanto herramienta para solucionar la falla de mercado del "bien público" que afecta a los bienes que son su objeto (de carácter no-rival y no-excluible). Así, una nueva norma constitucional debería fundarse en la promesa de la propiedad

* Abogado, Universidad de Chile. LL.M Derecho de la Competencia y Regulación, Universidad de Ámsterdam. Correo electrónico: juanpaiglesias@gmail.com

Recepción: 2021-05-29; aceptación: 2021-08-04. 
intelectual, a saber: optimizar el equilibrio entre creación y acceso al conocimiento, proveyendo de ese modo un marco general para que el legislador, los organismos públicos y los adjudicadores puedan luego actualizar dicho equilibrio en consideración al estado de desarrollo del país. En el artículo se propone un texto de norma constitucional que puede ser justificado en términos ralwsianos, es decir, desde un escenario hipotético de "posición original". Además, se explica que el texto propuesto no se agota en una mera declaración programática, enunciando así qué tipo de efectos concretos puede producir en el ordenamiento jurídico.

PAlabras Clave: Propiedad intelectual; Constitución; innovación; dominio público; mercado; tecnología.

ABSTRACT

The current constitutional provision on intellectual property (Art. 19 No. 25) is deficient since it is opaque regarding the economic and social objectives of said type of property. For this reason and considering the growth of the intangible-based economy in the $21^{\text {st }}$ century, it becomes

256 necessary and opportune to design a new constitutional provision that does not thoughtlessly refer to the general rule on property, in order to show the instrumental nature of intellectual property, as a tool to solve the "public good" market failure that affects the goods that are its object (which are non-rivalrous and non-excludable). Therefore, a new constitutional rule must be based on the promise of intellectual property, that is, optimizing the equilibrium between creation and access to knowledge, thus providing a general framework so that the legislator, public offices and adjudicators can then "update" such equilibrium considering the state of development of the country. The article proposes a text of constitutional provision that can be grounded in Ralwsian terms, that is, from a hypothetical scenario of "original position". Moreover, the article explains that the proposed text is not exhausted in a mere programmatic declaration, thus mentioning what type of concrete effects it can produce within the legal system.

KEYwORDs: Intellectual property; Constitution, Innovation; Public domain; Market; Technology. 


\section{Propiedad intelectual y Constitución en el Siglo XXI}

El siglo XXI ha consolidado el tránsito desde la riqueza fundada en activos tangibles a aquella basada en intangibles ${ }^{1}$. El avance de la digitalización, el desarrollo incremental de la inteligencia artificial y la creciente importancia del valor agregado en los procesos industriales son algunos de los fenómenos que demuestran dicho tránsito y que desafían la idoneidad de las normas jurídicas creadas durante el siglo XX.

Una buena parte de estas tendencias se enmarca jurídicamente en la esfera de la propiedad intelectual, entendiendo tal concepto en sentido amplio, es decir, abarcando los PI. Si bien la PI es solo un engranaje más dentro de un sistema nacional de innovación ${ }^{2}$, se trata de una pieza clave, pues constituye un nodo o punto de contacto entre la ciencia, la innovación y el emprendimiento. Así, además de incentivar la creación artística y tecnológica, la PI es un dispositivo normativo que permite operacionalizar diversas acciones, como atribuir autorías (individuales o colectivas), valorizar empresas (especialmente Pymes y startups), celebrar y ejecutar contratos de objeto tecnológico o artístico (por ejemplo, licencias, consorcios tecnológicos o acuerdos de investigación y desarrollo), servir como mecanismo de garantía y generar mercados tecnológicos ${ }^{3}$.

Sin embargo, a pesar de los beneficios generados por la PI, existen materias en las cuales se ha objetado su legitimidad. Así, en la industria del software en la década de 1980, los derechos de copyright sobre programas computacionales fueron resistidos por algunos -entre ellos Richard Stallman- por constituir una restricción a la libertad y a la creatividad de los desarrolladores, generando como respuesta el modelo alternativo del copyleft (jurídicamente plasmado en las condiciones de uso de la denominada General Public License). Por otro lado, en la industria farmacéutica, los derechos de patentes sobre ciertos medicamentos esenciales han sido objetados por impedir el acceso y tratamiento de personas o países sin recursos suficientes para financiarlos ${ }^{4}$.

${ }^{1}$ Como ha señalado el CTICI: "En el siglo XXI el conocimiento es un pilar indispensable para impulsar el progreso de las sociedades. No es el único, ni se basta por sí solo, pero sin él, el progreso y el desarrollo no se consiguen”. Consejo Nacional de Ciencia, Tecnología, Conocimiento e Innovación para el Desarrollo (2021), p. 13.

${ }^{2}$ Op. cit., p. 26.

${ }^{3}$ Los mercados tecnológicos son aquellos en los cuales se intercambian tecnologías protegidas por derechos de propiedad intelectual y sus sustitutos, separados de los productos o servicios sobre los que dichas tecnologías recaen. A modo de referencia, véanse las directrices relativas a la aplicación del art. 101 del Tratado de Funcionamiento de la Unión Europea a los Acuerdos de Transferencia de Tecnología (2014/C 89/03), párrafo 22.

${ }^{4}$ Un ejemplo reciente de esto es la solicitud presentada el 25 de mayo de 2021 por India, Sudáfrica, Bolivia y otros países a la Organización Mundial de Comercio para 
Pues bien, este artículo se funda en la idea de que los problemas de legitimidad de la PI pueden encontrar solución en la estructura misma de la PI y el diseño de sus elementos normativos internos ${ }^{5}$. De este modo, la discusión constitucional que ya se ha comenzado a dar en Chile a través del funcionamiento de la Convención Constitucional ${ }^{6}$, constituye una buena oportunidad para reflexionar sobre la PI y su relación con el desarrollo científico, tecnológico y artístico del país. En estos términos, la finalidad de este artículo es proponer una nueva norma constitucional sobre PI, cuyo tenor sea una respuesta -racionalizada y actualizada- a la siguiente pregunta: ¿Cómo balancear de manera óptima la creación y el acceso al conocimiento?

De esta pregunta surgen dos subpreguntas:

1) ¿Por qué esto es un asunto constitucional? y

2) ¿Es pertinente cambiar la norma que rige en la actual $C P R$ ?

En este acápite introductorio se adelantarán respuestas sencillas que serán luego profundizadas en las próximas secciones.

La respuesta a la primera pregunta es que sí es un tema constitucional, en la medida en que la $C P R$ instaura las instituciones normativas que definen las bases de la cooperación social. La creación y acceso al conocimiento de carácter tecnológico, artístico y científico constituyen in sumos esenciales para dicha cooperación y, en consecuencia, resulta preciso establecer en el ámbito constitucional un marco general que defina un horizonte o que sirva de brújula, tanto para el legislador como para los tribunales. Esto se explicará con más detalle en la sección v.

La respuesta a la segunda pregunta es que sí es pertinente cambiar la norma que rige en la actual $C P R$ sobre PI, esto es, el art. 19 n. ${ }^{\circ} 25$. La PI

eximir el cumplimiento de ciertas obligaciones establecidas por el tratado ADPIC en materia de patentes. Véase documento IP/C/W/669/Rev.1, disponible en https://docs. wto.org/dol2fe/Pages/SS/directdoc.aspx?filename=q:/IP/C/W669R1.pdf\&Open=True [fecha de consulta: 2 de julio de 2021].

${ }^{5}$ Así, es preciso notar que en estricto rigor el modelo del copyleft no es una negación, sino una aplicación del copyright. De lo que se trata no es de entregar un programa computacional al dominio público, sino que de establecer, mediante una licencia (fundada en la existencia de un derecho exclusivo), un régimen de distribución y uso que permita la generación de obras derivadas no-propietarias. Por otro lado, en materia de acceso a medicamentos esenciales, es factible incentivar la creación de esquemas excepcionales de cooperación entre titulares de patentes, fabricantes y órganos estatales (por ejemplo, consorcios tecnológicos) para acelerar procesos de innovación o, de ser necesario, activar procedimientos de licencias no voluntarias. Ambas estrategias presumen -y no niegan- la existencia de derechos de PI.

${ }^{6}$ La Convención Constitucional es la institución encargada de elaborar una nueva Constitución para Chile, en conformidad con lo dispuesto en el art. 130 y ss. de la actual Constitución Política de la República (reformada el 24 de diciembre de 2019, a través de la Ley n. ${ }^{\circ}$ 21200, que modifica el capítulo Xv de la Constitución). 
es una propiedad sui generis, pues ella tiene una justificación diferente a la propiedad que recae sobre bienes materiales y sobre bienes inmateriales no-tecnológicos o no-artísticos, que para los efectos de este artículo se denominará "propiedad tradicional". Así, si bien la $C P R$ contiene un tratamiento diferenciado entre propiedad tradicional (art. $\left.19 \mathrm{n} .^{\circ} 24\right)$ y PI (art. 19 n. ${ }^{\circ}$ 25), se argumentará que la segunda norma es deficitaria por resultar opaca respecto a los objetivos propios de la PI.

En consecuencia, de omitirse un tratamiento diferenciado entre ambos tipos o "especies" de propiedad, las leyes actuales o futuras sobre PI se diseñarán o interpretarán sobre la base de la regulación genérica de protección de la propiedad tradicional (ya sea, en materia de atributos, función social o expropiación). Dicha circunstancia, se sostendrá en este artículo, es problemática desde un punto de vista jurídico, social y económico.

En síntesis, el desafío de una nueva norma constitucional sobre PI es proveer un marco general y programático, para que el legislador, los órganos administrativos y los órganos jurisdiccionales puedan regular, interpretar y aplicar con mayor sistematicidad los derechos de PI en los distintos ámbitos jurídicos en que ellos intervienen (por ejemplo, registrabilidad de derechos, infracción de derechos, políticas de transferencia tecnológica y libre competencia).

Este texto se dividirá en cuatro secciones.

II) La primera expondrá el contenido de la norma constitucional actualmente vigente a la luz de su historia fidedigna.

III) La segunda sección explicará el problema de dicha norma constitucional, consistente en asimilar la propiedad tradicional a la PI, en circunstancias de que sus justificaciones filosóficas y económicas son divergentes.

IV) La tercera sección expondrá una propuesta de nueva norma constitucional que reconozca los objetivos propios de la PI y que sea aceptable en términos rawlsianos.

V) La cuarta sección señalará algunos de los efectos concretos que puede producir la norma constitucional propuesta en materia legislativa y administrativa (reglamentaria), en materia de libre competencia y en casos de competencia civil ordinaria.

Finalmente, se ofrecerán algunas conclusiones.

\section{EL ART. 19 N. ${ }^{\circ} 25$ DE LA $C P R$ : UNA NORMA OPACA}

Esta norma fue creada por la denominada "Comisión Ortúzar" entre los años 1976 y 1978, y luego complementada por la Ley n. ${ }^{\circ} 19742$ (publicada 
el año 2001), que incorporó "la libertad de crear y difundir las artes" en su inciso primero ${ }^{7}$. Así, el actual art. 19 n. ${ }^{\circ} 25$ de la CPR establece:

"[La Constitución asegura a todas las personas] $25^{\circ}$.- La libertad de crear y difundir las artes, así como el derecho del autor sobre sus creaciones intelectuales y artísticas de cualquier especie, por el tiempo que señale la ley y que no será inferior al de la vida del titular.

El derecho de autor comprende la propiedad de las obras y otros derechos, como la paternidad, la edición y la integridad de la obra, todo ello en conformidad a la ley.

Se garantiza, también, la propiedad industrial sobre las patentes de invención, marcas comerciales, modelos, procesos tecnológicos u otras creaciones análogas, por el tiempo que establezca la ley.

Será aplicable a la propiedad de las creaciones intelectuales y artísticas y a la propiedad industrial lo prescrito en los incisos segundo, tercero, cuarto y quinto del número anterior”.

Cabe mencionar que la primera versión de la norma propuesta en la Comisión Ortúzar, por Alejandro Silva Bascuñán, fue la siguiente:

"[La Constitución asegura] La protección de las creaciones científicas, literarias, artísticas o intelectuales de cualquiera índole y la de los inventos, descubrimientos, procesos, marcas comerciales, modelos y patentes técnicas u otras formas de carácter industrial.

La protección a que se refiere el inciso precedente comprende la del derecho de propiedad del autor o inventor por el tiempo que señale la ley y que no será inferior al de la vida del autor respecto de las creaciones intelectuales.

Es aplicable a las especies de propiedad comprendidas en este número, lo dispuesto en los incisos tercero, cuarto, quinto y sexto del número anterior"».

${ }^{7}$ Cabe notar que en las constituciones anteriores de Chile también existían normas de PI. Así, la Constitución de 1833 establecía en su art. 152: "Todo autor o inventor tendrá la propiedad exclusiva de su descubrimiento o producción por el tiempo que le concediere la ley; y si ésta exigiere su publicación, se dará al inventor la indemnización competente”. Por su lado, la Constitución de 1925 establecía en su art. 10 numeral 11. : "La propiedad exclusiva de todo descubrimiento o producción, por el tiempo que concediere la ley. $\mathrm{Si}$ ésta exigiere su expropiación, se dará al autor o inventor la indemnización competente".

${ }^{8}$ Historia de la Ley, Constitución Política de la República de Chile de 1980, art. 19 n. ${ }^{\circ} 25$, derecho de autor, pp. 5-6. Disponible en https://obtienearchivo.bcn.cl/obtienearchivo? $\mathrm{id}=$ recursoslegales/10221.3/390/1/Art19N25.pdf [fecha de consulta: 2 de julio de 2021]. 
Respecto a esta redacción, el también integrante de la referida comisión, Sergio Diez, realizó la siguiente observación:

"La indicación hecha por el señor Silva Bascuñán tiene el grave inconveniente de mezclar todas las cosas, y por querer que la Constitución tenga la parquedad que a él le gusta, se ha sido muy poco específicos en una materia que quizás históricamente haya tenido poca importancia, pero puede tenerla mucha"9.

La advertencia de Sergio Diez tenía mérito: hace cuarenta y cinco años la PI no tenía la relevancia que tiene hoy y, en consecuencia, su crítica a la parquedad de la norma propuesta por Alejandro Silva Bascuñán adquiere hoy pleno sentido. Sin embargo, la discusión suscitada entre Sergio Diez y Alejandro Silva Bascuñán sugiere que el desacuerdo sobre la norma en cuestión no era solo sobre "parquedad" versus "abundancia" regulatoria, sino, también, sobre la naturaleza de la PI. En efecto, para defender la parquedad de su propuesta, Alejandro Silva Bascuñán esgrimió que el objetivo de la norma en cuestión era:

"Que se entienda que lo que se quiere proteger es la propiedad. Ahora, la forma concreta y específica de esta protección no puede ser desarrollada en la Constitución, porque entonces vendría a resultar que el constituyente tendría que abarcar todo el campo de la preceptiva general de todo tipo de normas que tienen carácter general o abstracto" 10 .

Así, para dicho redactor, resultaba apropiado limitar el contenido de la norma a la simple enunciación de los bienes inmateriales protegidos (por ejemplo, creaciones literarias, marcas, patentes) más una referencia a su temporalidad, pues para el resto de sus elementos ya estaba disponible la regulación del derecho de propiedad tradicional. Esto se confirma en el inciso final del art. 19 n. ${ }^{\circ} 25$, el cual se remite a los incisos segundo, tercero, cuarto y quinto del art. 19 n. ${ }^{\circ} 24$. Lo importante era simplemente aclarar que la PI era un tipo más de propiedad.

En cierto sentido, la posición de Alejandro Silva Bascuñán es compatible con la regulación del Código Civil, que en su art. 584 establece: "Las producciones del talento o del ingenio son una propiedad de sus autores. Esta especie de propiedad se regirá por leyes especiales". Con todo, si bien la norma redactada por Andrés Bello en sí misma no expresa ninguna

${ }^{9}$ Historia de la Ley, op. cit., p. 12.

${ }^{10}$ Op. cit., p. 11. 
particularidad de la PI, sí es cuidadosa en advertir que ella se regirá por leyes especiales, dando a entender que existen razones sustantivas para adoptar un tratamiento diferenciado entre la propiedad tradicional, sea esta corporal (art. 582 del Código Civil) o incorporal (art. 583 del Código Civil) y la $\mathrm{PI}^{11}$.

En conclusión, la norma constitucional actual sobre PI es correcta solo en la medida en que la califica como propiedad, esto es, un derecho subjetivo de carácter real, con un titular exclusivo (conformado por una o más personas) y con efecto erga omnes. Se trata así de una "especie" de propiedad en los términos de Alejandro Guzmán Brito ${ }^{12}$, caracterizada por tener ciertas características especiales (i.e., límite temporal y objeto inmaterial). Sin embargo, la norma en comento es opaca respecto a las diferencias que existen entre la PI y la propiedad tradicional. Dicha opacidad o, en términos de Sergio Diez, "parquedad", consiste en no transparentar la relación existente entre desarrollo tecnológico, creación artística, tiempo y dominio público, que informa a la PI y que justifica su aceptabilidad social (como se explicará en la sección IV) ${ }^{13}$. Lo anterior genera una relación de carácter parasitaria de la PI respecto a la propiedad tradicional, en circunstancias que deberían constituir esferas normativas relativamente autónomas.

\section{LAS DIFERENCIAS ENTRE LA PI \\ Y LA PROPIEDAD TRADICIONAL DEBEN REFLEJARSE EN LA CONSTITUCIÓN}

El problema de que la norma contenida en el art. 19 n. ${ }^{\circ} 25$ sea parca u opaca, es que ella priva al legislador, jueces y operadores jurídicos de una brújula constitucional respecto a los fines de la PI. La falta de esta brújula puede generar inconsistencias respecto a los objetivos de la PI y los actos de legislación, regulación administrativa y de adjudicación que involucran derechos de PI. En este último sentido, cabe advertir que, en

${ }^{11} \mathrm{Al}$ respecto, Alejandro Guzmán Brito sostenía que los arts. 582, 583 y 584 establecían, cada uno, una especie de propiedad que, a su vez, pertenecían a un mismo género abstracto de propiedad (i.e., lo opuesto a lo ajeno). GuZMán (2006), pp. 138-139.

${ }^{12}$ Op. cit., pp. 141-142.

${ }^{13}$ Cabe notar que Ioannis Lianos y Rochelle Dreyfuss plantean una crítica similar al art. 17 de la Carta de Derechos Fundamentales de la Unión Europea, cuyo numeral primero se refiere a los atributos de la propiedad, su inviolabilidad y sus limitaciones, mientras que su numeral segundo se limita a indicar: "Se protege la propiedad intelectual". Así, los autores mencionados objetan la analogía entre ambos conceptos y notan la ausencia de una referencia a los límites de interés público en el ámbito de la PI. LiAnos \& Dreyfuss (2013), p. 48. 
atención a que la PI se estructura como un derecho subjetivo de carácter real, la norma constitucional no solo genera efectos verticales, sino, también, horizontales. Por ello, el diseño de la norma resultará decisivo tanto en procedimientos de control constitucional como en procedimientos ordinarios o especiales de aplicación de normas. Lo anterior, ya sea a través de la invocación directa ${ }^{14} \mathrm{o}$ indirecta de la norma, de acuerdo con la denominada "interpretación conforme a la Constitución"15.

A continuación:

1) Se expondrán las justificaciones filosóficas y económicas para fundamentar la protección de la propiedad tradicional, señalándose luego cómo estas resultan impertinentes respecto de la PI;

2) Luego, se profundizará en las razones que justifican la protección de la PI;

3) Por último, se explicará por qué resulta conveniente que la norma constitucional reconozca estos fundamentos.

\section{Las justificaciones para proteger la propiedad tradicional y su impertinencia para fundamentar la protección de la PI}

La propiedad tradicional ha sido justificada de diversas formas y en distintos contextos históricos. Este artículo solo se hará cargo de la noción moderna de propiedad, la cual admite ser caracterizada como una síntesis entre el liberalismo filosófico fundado en la autonomía de la voluntad y el liberalismo económico fundado en la economía de mercado, ambos desarrollados fundamentalmente en la Europa del siglo XVIII a través de pensadores como Immanuel Kant y Adam Smith. Al respecto Ernesto Vargas señala:

"Lo verdaderamente original en el surgimiento de la noción moderna de propiedad forma parte de un giro mayor mediante el cual tanto la tradición civil como el common law trataron de purgar sus doctrinas jurídicas de antiguos fundamentos aristotélicos, basados en conceptos de justicia conmutativa y distributiva, para articular su derecho privado en torno a la moderna idea de 'voluntad'" 16.

Teniendo a la vista la noción moderna de propiedad y su vínculo con la idea moderna de voluntad, a continuación, se repasarán las justificaciones

${ }^{14}$ Esto es lo que Pablo Marshall llama la "prescindencia de la dimensión legal del derecho". Marshall (2010), p. 52.

${ }^{15}$ Domínguez (1996), p. 111.

${ }^{16}$ Vargas (2021), pp. 248-249. 
filosóficas y económicas de la protección de la propiedad tradicional, para luego constatar su impertinencia para fundamentar la protección de la PI.

\section{a) Consideraciones filosóficas}

En lo que respecta a la esfera filosófica, la idea moderna de voluntad es tributaria de la teoría de la apropiación sobre la base del trabajo propuesta por John Locke y la teoría del reconocimiento de la personalidad elaborada por Georg W. F. Hege ${ }^{17}$. Cabe reparar en que ambas teorías han sido también propuestas para justificar la PI, pero con un desempeño insatisfactorio, dado que no logran dar cuenta de su objetivo principal (que, como se verá más adelante, es solucionar el problema del "bien público").

En efecto, las condiciones exigidas por John Locke para la apropiabilidad de una cosa son:

i) Que haya de esas cosas una cantidad suficiente y de calidad no inferior a disposición de los demás y

ii) Que el individuo que las apropia pueda "usarlas" en provecho propio o de los suyos antes de que se deterioren ${ }^{18}$.

Estas condiciones se ajustan bien a recursos tales como la tierra y el agua (los ejemplos son del mismo John Locke). Sin embargo, como afirma Seana Shiffrin, la naturaleza de las obras intelectuales parece no ajustarse a ellas, 264 sobre todo considerando su carácter no-rival y no-excluible ${ }^{19}$.

Por otro lado, en cuanto a la teoría de la personalidad de Georg Hegel, la sección $\$ 46^{20}$ de su obra La filosofía del derecho explica la propiedad como la voluntad "objetivada" del individuo, otorgando así una suerte de validación de su propia personalidad. Luego, la sección $\$ 67^{21}$ de la misma obra afirma la inalienabilidad de las habilidades especiales del individuo, incluyendo las "espirituales", a fin de conservar su personalidad.

Como ha explicado Iñigo De La Maza, la lectura de estas secciones permitiría "justificar la existencia de lo que denominamos propiedad in-

${ }^{17}$ VARgas (2021), p. 249.

${ }^{18}$ Barceló (1993), p. 256.

${ }^{19}$ Shiffrin (2001), p. 141.

20 "Debido a que mi voluntad personal, esto es, mi voluntad como individuo, se me hace objetiva en la propiedad, ésta adquiere el carácter de propiedad privada, y la propiedad común que por naturaleza puede ser poseída por un individuo adquiere la determinación de comunidad disoluble en la que puedo, a mi arbitrio, dejar o no mi parte". Véase traducción de Carla Cordua. Condua (1994), p. 438.

21 "De mis habilidades especiales, corporales o espirituales y de mis posibilidades de actividad puedo enajenar a otro producciones particulares y un uso de ellas limitado en el tiempo, porque con esta limitación ellas mantienen una relación exterior con mi totalidad y universalidad. Con la enajenación de todo mi tiempo concreto de trabajo y de la totalidad de mi producción, convertiría en propiedad de otro mi sustancia misma, mi actividad y realidad universal, mi personalidad [...]”. Véase traducción de Carla Cordua. Op. cit., p. 441. 
telectual como una condición para la constitución de la personalidad" y que, en cuanto a su enajenación, "sus límites se encuentran precisamente en el momento en que lo enajenado lesiona la personalidad del sujeto" 22 . Lo anterior asume que sería la personalidad misma del creador la que se manifiesta en la obra ${ }^{23}$. Si bien estas ideas permiten explicar la existencia de los derechos morales del autor (i.e., paternidad e integridad), que la tradición continental ha comprendido como inalienables ${ }^{24}$, ellas no dan cuenta de la esfera propiamente patrimonial de la PI.

\section{b) Consideraciones económicas}

La falta de idoneidad de las justificaciones filosóficas de la propiedad tradicional para dar cuenta del fenómeno de la PI es una materia de segundo orden, dado que, desde la perspectiva del racionalismo occidental de orden capitalista, lo definitivo son las justificaciones de orden económico.

$\mathrm{Al}$ respecto, en un artículo titulado "Por qué proteger constitucionalmente la propiedad", Enrique Barros realiza una breve revisión histórica de las razones económicas -que él denomina "pragmáticas"- para proteger la propiedad. Estas justificaciones serían tres:

i) Los problemas asociados a la propiedad compartida, expuestos seminalmente en la publicación titulada "La tragedia de los comunes", de Garret Hardin,

ii) La relevancia de la propiedad privada como base de un sistema de intercambios espontáneos, defendida paradigmáticamente por Friedrich Hayek y

iii) La idea de que la propiedad optimiza el uso de los recursos en términos de eficiencia de Vilfredo Pareto $^{25}$.

Luego de exponer someramente estos tres argumentos, Enrique Barros afirma que:

"Estas razones pragmáticas no pueden ser ignoradas al entender el trasfondo social del reconocimiento constitucional y civil de la propiedad y de su expansión a bienes incorporales e inmateriales [...]”26.

Si bien el autor no afirma de forma expresa que las razones previamente indicadas sirven para justificar también la PI, sí parece sugerirlo de

${ }^{22}$ De La Maza (2006), p. 65.

${ }^{23}$ LYPSZYC (1993), p. 169.

${ }^{24}$ En Chile, la inalienabilidad de los derechos morales se encuentra establecida en el art. 16 de la Ley n. ${ }^{\circ} 17336$.

${ }^{25}$ Barros (2021), p. 225.

${ }^{26}$ Ibid. 
modo implícito al extenderlas a los bienes "incorporales e inmateriales". Este artículo sostiene que dicha extrapolación no es correcta.

En este punto es necesario introducir algunas clarificaciones. Los derechos de PI son cosas incorporales -en tanto "derechos" 27 - que recaen sobre bienes inmateriales que, a su vez, pueden caracterizarse como "cápsulas de información" 28 . A grandes rasgos, estas cápsulas de información pueden referirse a una solución tecnológica (en el caso de las patentes y, en cierta medida, a las variedades vegetales), a expresiones creativas (en el caso de los derechos de autor) o a signos distintivos para identificar el origen empresarial o geográfico de productos o servicios (en el caso de las marcas comerciales, denominaciones de origen e indicaciones geográficas) o, bien, para identificar requisitos o características de productos o servicios (en el caso de las marcas de certificación) ${ }^{29}$.

Lo relevante es que este tipo de bienes inmateriales son lo que en literatura económica se denominan "bienes públicos" ${ }^{30}$, es decir, bienes "norivales" y "no-excluibles" respecto a su uso y consumo ${ }^{31}$. Son no-rivales en la medida en que más de una persona puede usar la información de forma simultánea. Son no-excluibles en la medida en que la información, por su naturaleza ubicua, no permite excluir de modo eficaz a un consumidor del acceso al recurso (como sí es posible hacer respecto de un predio) ${ }^{32}$. También se puede agregar que son no-deteriorables en la medida en que Civil.

${ }^{27}$ Esto siguiendo la definición de cosas incorporales del art. 565 inciso final del Código

${ }^{28}$ Para una explicación de la información como commodity, en tanto protegida por derechos de PI, véase Arrow (1962), pp. 614-619.

${ }^{29}$ Las marcas de certificación fueron incorporadas a la Ley n. ${ }^{\circ} 19039$ (nuevo art. 23 bis B) a través de la nueva Ley n. ${ }^{\circ} 21355$ (denominada "Ley Corta de INAPI"). Al tiempo de la redacción de este artículo, el proyecto de ley aún se encuentra en espera de promulgación.

${ }^{30}$ Los bienes públicos son diferentes a los bienes comunes, cuyo consumo y uso sí es rival (por ejemplo, pescados en altamar). Ejemplos de bienes públicos materiales son los semáforos o los faros. Se debe notar que la palabra 'público' aquí no hace referencia a la forma (estatal) de provisión del bien, sino que a su capacidad de generar externalidades positivas. De este modo, un bien público, en sentido económico, puede ser creado y provisto por el estado o por un privado.

${ }^{31}$ Lianos \& Dreyfuss (2013), pp. 49-50.

${ }^{32}$ Como señalan William Landes y Richard Posner: "Intellectual property tends to be particularly costly to protect. An idea cannot be seen in the way a piece of land can be [...] Moreover, the public good character of intellectual property can make it costly to prevent misappropriation and exclude free riders in the absence of legal protection". LANDES \& Posner (1987), p. 267. (Traducción libre: "La propiedad intelectual tiende a ser particularmente costosa de proteger. Una idea no puede ser vista de la forma en que una porción de tierra puede ser vista [...] Además, el carácter de bien público de la propiedad intelectual puede hacer que sea costoso prevenir la apropiación indebida y excluir a agentes oportunistas en la ausencia de protección legal"). 
el consumo de la información por parte de una persona no disminuye la calidad del recurso para el resto ${ }^{33}$.

Estas características no son propias de todo tipo de bien inmaterial. Así, el oxígeno y el espectro radioeléctrico son bienes inmateriales -en realidad, "incorporales" ${ }^{34}$-, pero no públicos, dado que su consumo es de carácter rival. Por esta razón, para asegurar un uso eficiente de dichos recursos, se han implementado sobre ellos sistemas de asignación de propiedad tradicional (por ejemplo, bonos de carbono o concesiones de espectro radioeléctrico). Por otro lado, las criptomonedas, que son un bien propiamente inmaterial, también son rivales y, por su configuración criptográfica, de carácter excluible. Por ello, el sistema de propiedad tradicional también es congruente con su naturaleza.

Las consideraciones anteriores tienen por finalidad demostrar que no todos los bienes inmateriales tienen las mismas características. Así, mientras algunos bienes inmateriales comparten las características de los bienes materiales sobre los cuales recae la propiedad tradicional (rivalidad y excluibilidad), los bienes inmateriales sobre los que recaen los derechos de PI, esto es, las "cápsulas de información" ya referidas, no las comparten (pues, como ya se señaló, la naturaleza de la información es no-rival y no-excluible).

El corolario de lo anterior es que las razones pragmáticas descritas por Enrique Barros no son pertinentes para justificar la protección de la PI. En primer lugar, los problemas de la propiedad compartida suponen que el recurso en disputa es de carácter rival, deteriorable y excluible. Sin ir más lejos, el ejemplo paradigmático de Garret Harding consistía en "un pastizal abierto" respecto del cual distintos pastores, actuando individualmente, incluían en él más y más animales de su rebaño, ocasionando un sobrepastoreo que terminaba por dañar el pastizal en perjuicio de todos

${ }^{33}$ En este sentido, es famosa la frase de Thomas Jefferson: "He who receives an idea from me, receives instruction himself without lessening mine; as he who lights his taper at mine, receives light without darkening me". Liscomb \& ELLERY (1905), p. 334. (Traducción libre: "El que recibe una idea de mí, recibe formación él mismo sin disminuir la mía; como el que enciende su vela en la mía, recibe luz sin oscurecerme").

${ }^{34} \mathrm{El}$ oxígeno y el espectro radioeléctrico, si bien no pueden ser percibidos por los sentidos (al menos no en la forma en que el art. 565 inciso 2. ${ }^{\circ}$ del Código Civil supone), sí tienen una extensión física en el espacio a nivel de partículas u ondas y, por ello, no son bienes inmateriales en sentido estricto. Existe aquí un problema de nomenclatura originado por el tenor del art. 565 inciso $3 .^{\circ}$ del Código Civil, que define las cosas incorporales no como aquellas que no pueden ser percibidas por los sentidos, sino como aquellas que "consisten en meros derechos". De este modo, las cosas inmateriales parecen estar excluidas de las categorización binaria "corporal"/“incorporal", ya que ellas no pueden ser percibidas por los sentidos ni tampoco consisten en derechos. 
los pastores ${ }^{35}$. Por lo ya señalado, la metáfora del pastizal no se ajusta al carácter no-rival, no-deteriorable y no-excluible de las "cápsulas de información" que busca proteger la PI.

En segundo lugar, en cuanto al rol de la propiedad privada como base de un sistema de intercambios espontáneos que, a su vez, incentiva la creación de la riqueza, lo cierto es que esta idea tampoco se ajusta a la naturaleza de la información. En efecto, el mismo Friedrich Hayek afirmaba con elocuencia:

"The growth of knowledge is of such special importance because, while the material resources will always remain scarce and will have to be reserved for limited purposes, the uses of new knowledge (where we do not make them artificially scarce by patents of monopoly) are unrestricted" 36 .

De este modo, reconociendo la naturaleza no escasa de la información, el autor advertía sobre los riesgos de extender el sistema de propiedad tradicional a las invenciones y creaciones, precisamente por la distorsión que ello podría generar para un sistema de mercado:

"I am thinking here of the extension of the concept of property to such rights and privileges as patents for invention, copyright, trade-marks, and the like. It seems to me beyond a doubt that in these fields a slavish application of the concept of property as it has been developed for material things has done a great deal to foster the growth of monopoly and that here drastic reforms may be required if competition is to be made to work" ${ }^{37}$.

Existe, entonces, una cierta tensión entre un sistema de intercambios espontáneos fundado en la libre competencia y la idea de extender la

${ }^{35}$ HARDING (1968).

${ }^{36}$ HAYEK (1960), p. 39. (Traducción libre: "El crecimiento del conocimiento es de especial importancia porque, mientras los recursos materiales siempre se mantendrán escasos y tendrán que reservarse para propósitos limitados, los usos del nuevo conocimiento (donde no los hagamos artificialmente escasos mediante patentes de monopolio) no tienen restricción").

${ }^{37}$ HAYEK (1948), pp. 113-114. (Traducción libre: "Estoy pensando aquí en la extensión del concepto de propiedad a derechos y privilegios como las patentes de invención, derechos de autor, marcas comerciales y similares. Me parece más allá de toda duda que en estos campos una aplicación servil del concepto de propiedad tal como se ha desarrollado para las cosas materiales ha contribuido en gran medida a fomentar el crecimiento del monopolio y que aquí reformas drásticas pueden ser necesarias si se desea que la competencia funcione"). 
propiedad tradicional sobre lo que más arriba se denominó "cápsulas de información". Esto, ya que dicha extensión puede generar derechos de señorío exclusivos demasiado amplios y "cerrados", que obstaculicen el proceso competitivo y la diseminación social de la información. Esta misma consideración permite así descartar la tercera razón pragmática indicada por Enrique Barros para justificar la PI, pues, por lo ya explicado, la optimización del uso de la información difícilmente puede sostenerse en el paradigma de la propiedad tradicional.

\section{La justificación propia y sui generis de la PI}

Habiendo descartado las razones filosóficas y económicas que justifican la protección de la propiedad tradicional, corresponde ahora referirse a la PI. La razón fundamental que justifica la existencia de esta especie de propiedad es de tipo económica y eminentemente instrumental, y consiste en solucionar la falla de mercado del "bien público", también expresada como el "problema del polizón" (o free rider), o el problema de los incentivos. Para comprender esta solución se requiere adoptar una perspectiva dinámica, esto es, una mirada que considere el factor tiempo.

Como sugirió el economista Joseph Schumpeter a mediados del siglo xx, "el análisis dinámico es el análisis de secuencias en el tiempo" 38 y, por ello, toma en consideración no solo las circunstancias económicas en la situación presente -como lo hace el análisis estático- "sino también su estado en puntos temporales precedentes, y las expectativas sobre sus valores futuros" 39 . Así, la consideración del factor tiempo permite diferenciar dos momentos: el de la creación de un bien y el posterior en que dicho bien se distribuye. Si bien ambos están separados en el tiempo, se encuentran económicamente interrelacionados.

En efecto, si una persona ocupa tiempo y recursos para producir una cápsula de información que tenga utilidad social, pero que luego todos pueden consumir y gozar sin necesidad de pagar por dicho uso, la generación de estos bienes quedaría entregada al reducido ámbito del comportamiento altruista. De este modo, la PI tiene por objetivo permitir al creador o productor de un bien anticipar, en el momento de la creación, la obtención de un retorno a su inversión en el momento -ulterior- de la distribución ${ }^{40}$.

${ }^{38}$ Schumpeter (2012), número de posición en edición Kindl 2131-2132. (Traducción libre al español).

${ }^{39} \mathrm{Ibid}$. (Traducción libre al español).

${ }^{40}$ Con todo, existen casos en que las denominadas "ventajas de primer movimiento" (first mover advatanges) pueden resultar suficientes para incentivar la creación de un nuevo producto. En efecto, ser el primero en llegar al mercado tiene un valor susceptible de ser capitalizado mediante mecanismos ajenos a la PI, tales como la posibilidad de alcanzar 
El mecanismo que se ha demostrado más eficaz para lograr ese objetivo es el otorgamiento de un derecho exclusivo sobre el bien, que impide a otros aprovecharse de él sin la autorización de su titular ${ }^{41}$. Como explica Ariel Katz:

"Because they are given a right to exclude others from their work, creators can effect artificial scarcity of their intellectual goods, allowing the price of the intellectual goods to increase and the initial investment to be recouped" 42 .

La PI tiene así un carácter instrumental, constituyéndose como una herramienta diseñada con la intención de alterar el mercado para conseguir un resultado concreto. En efecto, su objetivo es conferir a su titular poder de mercado por la vía de eliminar una porción de productos sustitutos (i.e., los productos infractores), a fin de que pueda exigir un precio o royalty supracompetitivo (i.e., por sobre el costo marginal) para recuperar la inversión realizada al crear y desarrollar el producto, más un margen de utilidad $^{43}$. Otras formas en que este poder de mercado se puede manifestar de forma legítima es a través de la presentación de acciones judiciales contra agentes de mercado que comercialicen productos infractores (por ejemplo, una acción civil de "cesación") $)^{44}$ o la denegación de conferir a terceros licencias de uso o acceso al bien protegido.

rápidamente economías de escala o acceder a un aprendizaje más rápido que el resto de los competidores respecto a la tecnología desarrollada. Sin embargo, una de las ventajas de primer movimiento más eficaces es lograr que el producto introducido al mercado sea asociado por los consumidores a la marca comercial de su fabricante, la cual sí constituye un mecanismo de propio de la PI.

${ }^{41}$ Con todo, los derechos de PI no son los únicos mecanismos para incentivar la creación e innovación. Al respecto y desde una perspectiva crítica a la PI, Dean Baker, Arjun Jayadev y Joseph Stiglitz mencionan el financiamiento directo a través de mecanismos centralizados y descentralizados, y el financiamiento a través de sistemas de “premios”. BAKer, JayAdeV \& Stiglitz (2017), pp. 11-12.

${ }^{42}$ Katz (2007), p. 841. (Traducción libre: "Debido a que se les otorga un derecho a excluir a otros de su trabajo, los creadores pueden provocar una escasez artificial de sus bienes intelectuales, permitiendo que el precio de los bienes intelectuales aumente y la inversión inicial se recupere").

${ }^{43}$ Sin embargo, cabe tener presente que aun en materia de patentes de invención, que son los derechos de PI más robustos en cuanto a la extensión de su objeto de protección, la captura de valor no es óptima. En este sentido, David Teece advierte que las patentes no trabajan en la práctica como lo hacen en la teoría y rara vez, si es que alguna, confieren perfecta apropiabilidad. La apropiabilidad es aún más débil tratándose de tecnologías basadas en conocimiento codificado (es decir, no tácito) y fácilmente observable, dado que dichas características facilitan la llamada "ingeniería reversa" del bien. TEECE (1986), p. 287.

${ }^{44}$ Art. 106 letra a) de la Ley n. ${ }^{\circ} 19039$. 
Por lo anterior, a diferencia de la propiedad tradicional, la PI tiene una vocación monopólica ${ }^{45}$. La propiedad tradicional no confiere un monopolio, sino que ella solo otorga la facultad de controlar un bien en particular y sus frutos (entre otros, un yacimiento de petróleo), mas no sus sustitutos. El monopolio solo se produce si una persona acapara un conjunto de bienes (por ejemplo, todos los yacimientos de petróleo de una región), circunstancia que podría levantar alertas para un ente regulador o una autoridad de competencia. En cambio, la vocación monopólica de la PI, en principio, no debería ser mirada con sospecha, dado que obedecería al comportamiento esperado por el diseño legal ${ }^{46}$. En este sentido, en la literatura se han distinguido las rentas económicas obtenidas como retorno a la innovación y por un tiempo limitado (denominadas "rentas schumpeterianas"), cuya captura por el innovador debería ser permitida ${ }^{47}$, de las rentas meramente monopólicas, cuya captura puede ser objetada mediante las normas de libre competencia.

De este modo, el efecto anticompetitivo que genera un derecho de PI desde una perspectiva de eficiencia asignativa estática (en el corto plazo), está compensado por los incentivos a la innovación desde una perspectiva de eficiencia dinámica (en el largo plazo) ${ }^{48}$. Innovación significa la creación de nuevos productos o la mejora de los ya existentes, beneficiando a los consumidores tanto en la calidad como en el precio de los productos. Así, como sugieren Roger Blair y Wenche Wang, la PI supone "el sacrificio de cierto bienestar del consumidor en el presente para mejorar el bienestar del consumidor en el futuro" ${ }^{49}$. En este sentido, resulta ilustrativo lo señalado en las Directrices de Transferencia Tecnológica de la Unión Europea:

${ }^{45}$ Cabe aclarar que un derecho de PI difícilmente creará un monopolio en términos económicos, ya que normalmente existirán sustitutos -directos o indirectos- que no infringirán el derecho. A modo de ilustración, las Directrices Antimonopolio para el Licenciamiento de la Propiedad Intelectual elaboradas por las autoridades de competencia de Estados Unidos indican que las autoridades de competencia "no presumirán que una patente, copyright o secreto comercial necesariamente confieren poder de mercado a su titular". Department of Justice \& Federal Trade Commission (2017), p. 4. (Traducción libre al español). En el mismo sentido, véase HABER (2016), pp. 812-813.

${ }^{46}$ Así lo entendió el Tribunal Constitucional chileno en sentencia dictada el año 2014 a propósito de un requerimiento de inaplicabilidad por inconstitucionalidad de los arts. 48 y 108 letra b) de la Ley n. ${ }^{\circ}$ 19039: "Que el monopolio que se protege sobre los inventos, marcas y procesos tecnológicos constituye un incentivo al desarrollo técnico e industrial, puesto que de carecer de tal garantía, no se invertiría en su investigación científica y aplicación tecnológica". Codelco con A. (2014), cons. 17. .

${ }^{47}$ Petit \& Teece (2021), p. 35.

${ }^{48}$ MotTa (2009), pp. 55-58.

${ }^{49}$ Blair \& Wenche (2017) p. 204. (Traducción libre al español). 
"Para no restringir la competencia dinámica y mantener los incentivos que existen para innovar, hay que evitar que se limite indebidamente la libertad del innovador de explotar aquellos derechos de propiedad intelectual que puedan tener valor. Así pues, en principio hay que permitir que el innovador saque el suficiente provecho de los proyectos que hayan tenido éxito para mantener los incentivos a la inversión, teniendo en cuenta los proyectos que fracasan" 50 .

La PI, a diferencia de la propiedad tradicional, no busca optimizar el uso de un recurso ya existente, sino que es una herramienta para generar un nivel óptimo de creación e innovación. Dicho de otra forma, la PI permite que una cápsula de información sea creada, pero a cambio de transformarla en un bien relativamente escaso e inequitativamente distribuido $^{51}$. Así, de no ser por la PI, la información podría ser equitativamente distribuida (es decir, accesible para todos), pero apenas sería creada.

De esta forma, la PI está atravesada por una tensión inmanente a ella misma, entre creación de bienes socialmente útiles y el acceso a los mismos. Esto significa que la PI es una solución de compromiso entre dos objetivos divergentes. Como advierten William Landes y Richard 272 Posner, el derecho de autor "negocia" (trades off) los costos de limitar el acceso a una obra contra los beneficios de proporcionar los incentivos para crear la obra en primer lugar. Así, lograr el correcto equilibrio entre acceso e incentivos es el problema central de la propiedad intelectual ${ }^{52}$. Este balance debe realizarse con cuidado. En efecto, derechos de PI muy débiles reducen los incentivos a crear, ya que no permiten recuperar los esfuerzos económicos del innovador o creador, mientras que derechos de PI muy fuertes obstaculizan el acceso a los bienes generados, pues el alcance y duración de la exclusividad permitirá al titular impedir a terceros más usos de la información protegida.

${ }^{50}$ Directrices relativas a la aplicación del art. 101 del Tratado de Funcionamiento de la Unión Europea a los acuerdos de transferencia de tecnología (2014/C 89/03), párrafo 8.

${ }^{51}$ Para los propósitos de este artículo, la distribución de los bienes protegidos por la PI (i.e., cápsulas de información) se entiende como un problema de acceso. En efecto, para acceder a la información protegida por un derecho de PI ( $v r$. gr., una obra artística o una solución tecnológica) se requiere obtener una autorización o licencia de parte de su titular, invocar una regla de exención de autorización, esperar a que la protección otorgada por el derecho expire (por duración o caducidad) y la información pase al dominio público o, bien, iniciar un procedimiento de licencia no voluntaria. Todas estas formas de acceso determinan el modo en que la información protegida por derechos de PI se distribuirá entre los agentes interesados. En estos términos, en este artículo se habla de distribución y acceso de manera intercambiable.

${ }^{52}$ Landes \& Posner (1989), p. 326. 
En el ámbito legal, el balance entre creación y acceso a las cápsulas de información protegidas por derechos de PI se puede calibrar a través de distintos elementos que forman parte de la estructura misma de dichos derechos. Estos son: su duración, su extensión o alcance de su objeto de protección, sus excepciones al régimen de autorización de uso y su agotamiento (o en inglés, exhaustion). Estos elementos varían respecto de cada tipo de derecho de PI y, en consecuencia, resulta imprescindible distinguirlos entre sí.

En la actualidad, los derechos de PI que existen en el ordenamiento legal chileno son los siguientes:

i) Patente de invención,

ii) Patente de modelo de utilidad,

iii) Diseño industrial,

iv) Dibujo industrial,

v) Esquemas de trazado o topografías de circuitos integrados,

vi) Marcas comerciales,

vii) Indicaciones geográficas,

viii) Denominaciones de origen,

ix) Derechos de autor (incluyendo los derechos conexos) y

(x) Variedades vegetales.

Todos estos derechos otorgan exclusividad sobre una cápsula de información específica, de manera que, en principio, solo su titular -o conjunto de titulare ${ }^{53}$ - puede explotarla comercialmente. Como se observa, en esta lista no se encuentra la protección legal de la información no divulgada (o "secreto comercial" ${ }^{54}$ ) ni la protección de la información suministrada a la autoridad para la obtención de registros ${ }^{55}$, ya que estos no son derechos de PI propiamente tales. Bajo la misma lógica, se excluye el conocimiento técnico derivado de la experiencia (know-how), en la medida en que este no pueda ser incorporado a alguno de los derechos de PI antes mencionados. De este modo, por no constituir derechos exclusivos, sino tipificaciones de conductas desleales, no resulta correcto incluir estos ámbitos de protección bajo la especie de propiedad de la $\mathrm{PI}^{56}$.

${ }^{53}$ Entre los titulares se deben considerar los “originarios" y los “derivados”. Los primeros son aquellos en cuyo patrimonio nace el derecho de PI. Los segundos son aquellos que cuentan con una autorización del titular originario para explotar -sea de forma exclusiva o compartida- el derecho de PI.

${ }^{54}$ Art. 86 y ss. de la Ley n. 19039 (anteriormente denominados "secretos empresariales").

${ }^{55}$ Art. 89 y ss. de la Ley n. ${ }^{\circ} 19039$.

${ }^{56}$ La protección de la información no divulgada no tiene la estructura de derecho exclusivo, pues si un tercero sin deber de reserva o confidencialidad arriba a la misma información de manera accidental o utilizando ingeniería reversa, sí podría utilizarla. De este 
Ahora bien, los derechos de PI pueden dividirse en dos grandes categorías, según su objeto. Por un lado, están los derechos que confieren exclusividad sobre un determinado bien material o inmaterial de carácter artístico (a saber, pieza musical) o tecnológico (por ejemplo, medicamento), con el fin de eliminar bienes sustitutos en el mercado. Esta categoría comprende: las patentes de invención, de modelo de utilidad, diseños industriales, dibujos industriales, esquemas de trazado o topografías de circuitos integrados, variedades vegetales y los derechos de autor. Por otro lado, están los derechos que confieren exclusividad sobre un determinado signo distintivo con el fin de eliminar del mercado no bienes, sino usos no autorizados de dichos signos (para efectos de capitalizar el origen comercial, geográfico o cultural de un producto o servicio). Esta segunda categoría comprende: las marcas comerciales, marcas de certificación, las indicaciones geográficas y las denominaciones de origen.

En otras palabras, mientras la primera categoría de derechos de PI busca evitar la reproducción o uso no autorizado de bienes (sin importar su origen empresarial), la segunda busca evitar que se produzca confusión respecto al origen de dichos bienes (sin importar cuáles sean). La importancia de diferenciarlas es que los modos de acceso o distribución del objeto protegido por el derecho de PI varían.

$274 \quad$ Así, en primer lugar, mientras los derechos comprendidos en la primera categoría tienen una duración limitada, aquellos comprendidos en la segunda tienen una duración indefinida ${ }^{57}$. Esta diferencia se explica porque los derechos de la primera categoría se enmarcan en un verdadero contrato social entre el creador y el Estado, mediante el cual el segundo ofrece un "monopolio" temporal al primero a cambio de que este renuncie a mantener la información en secreto y la revele a la sociedad, de modo

modo, los secretos comerciales no constituyen un derecho exclusivo sobre una cápsula de información, sino un derecho a restringir el acceso desleal a dicha cápsula. Por esta misma razón el art. $1 .^{\circ}$ de la Ley n. ${ }^{\circ} 19039$ distingue los "derechos de propiedad industrial" (enunciados en el inciso primero) de "las conductas consideradas desleales en el ámbito de la protección de la información no divulgada" (inciso segundo). En la misma línea, la Ley n. ${ }^{\circ} 21355$ reemplaza la expresión 'titular' en el art. 87 de la Ley n. ${ }^{\circ} 19039$, por la de "legítimo poseedor", para referirse al beneficiario de la protección legal conferida por las normas de secreto comercial. Con todo, cabe advertir que esta posición es objeto de discusión. Así, en Estados Unidos la Corte Suprema ha afirmado que el secreto comercial (trade secret) es una forma de propiedad, ya que es asignable, puede formar parte de un trust y puede pasar a un trustee en caso de quiebra. Ruckelshaus v. Monsanto Co. (1984).

${ }^{57}$ De acuerdo con la Ley n. ${ }^{\circ} 19039$, las marcas comerciales tienen una duración de diez años, pero con posibilidad de solicitar renovaciones sucesivas (art. 24), mientras que las denominaciones de origen y las indicaciones geográficas tienen una duración indefinida (art. 100). 
que, luego de un periodo, ella sea incorporada al dominio público ${ }^{58}$. De esta forma, los derechos de primera categoría están diseñados para que estos siempre formen parte del dominio público, mientras que los derechos de segunda categoría no (salvo casos específicos) ${ }^{59}$.

En segundo lugar, las excepciones de autorización para el uso de los bienes protegidos durante la vigencia de los derechos de PI son también diferentes. Así, respecto a los derechos de primera categoría, existen reglas de excepción que, en general, autorizan el uso del bien protegido para actividades incidentales y no comerciales, o con fines investigativos. Por otro lado, respecto a los derechos de segunda categoría no existen reglas semejantes, pues como ya se indicó, dichos derechos no recaen sobre un bien artístico o tecnológico, sino que sobre un signo distintivo. De este modo, si bien no existen autorizaciones de uso explícitas, sí debe entenderse que mientras el uso del signo realizado por el tercero no induzca a confusión al público consumidor respecto a lo que el signo distingue (vr. gr., procedencia empresarial u origen geográfico), no se configuraría una infracción al derecho de $\mathrm{PI}^{60}$.

Si bien las diferentes maneras en que la estructura interna de los derechos de PI (de ambas categorías) equilibran la creación y el acceso se encuentran reguladas por la ley, es conveniente que ellas también tengan un

${ }^{58}$ La extensión temporal y material de este "monopolio" varía en los distintos derechos de PI de la primera categoría. En materia de patentes (comprendiendo por tales las de invención, de modelo de utilidad y los diseños y dibujos industriales), en principio, la extensión de la protección depende del grado de innovación. Así, mientras más "radical" sea la innovación más fácil será protegerla a través de una patente de invención. A la inversa, mientras menos radical y funcional sea la innovación, más probable es que ella solo pueda ser protegida a través de un modelo de utilidad o un diseño industrial. La diferencia es que la protección de las patentes de invención no se limita a una funcionalidad o forma concreta, sino que a la idea que subyace detrás de dicha forma o funcionalidad, alcanzando así a "todas las realizaciones que puedan estimarse como cumplidoras de la idea inventiva", esto es, a los llamados "equivalentes técnicos". CORTÉs (2012), p. 206.

${ }^{59}$ Una marca comercial puede desplazarse al dominio público en caso de perder su distintividad y devenir en una expresión genérica (esto es, una designación usual de un producto o servicio). En estos casos, por la "vulgarización" que sufre la marca, esta se convierte en un insumo significativo para la comunicación social, debiendo quedar a disposición de todos. Dreyfuss (1990), p. 423. Cabe advertir, además, que la Ley n. ${ }^{\circ} 21355$ reconoce este fenómeno como una causal de caducidad, en el nuevo art. 27 bis A de la Ley.$^{\circ} 19039$.

${ }^{60}$ Con todo, el uso no autorizado de una marca, aun cuando no genere confusión, sí podría generar daños patrimoniales o extrapatrimoniales a personas jurídicas (por ejemplo, si la marca se utiliza en un medio de comunicación masivo solo para efectos de difamar a la persona jurídica). En estos casos, la demanda indemnizatoria no se fundaría en la Ley n. ${ }^{\circ} 19039$ sino en el denominado derecho a la imagen o fama comercial de las personas jurídicas. Pizarro (2006), p. 145. 
respaldo constitucional. Por supuesto, la norma de la Carta Fundamental no debe reparar en detalles, pero sí ofrecer un marco general que otorgue seguridad jurídica a los arreglos normativos ya mencionados, así como también un espacio regulatorio para ser modificado en el largo plazo de acuerdo con las necesidades de la sociedad. Así, podrán existir momentos o sectores específicos del mercado en que sea necesario "contraer" los derechos de PI y otros en que sea necesario "expandirlos".

\section{Donde existe una razón diferente, debe existir una disposición diferente}

El punto central para los fines de este artículo es que en atención a que las razones para justificar la protección de la PI son diferentes a aquellas para justificar la protección de la propiedad tradicional, el diseño de la norma constitucional para proteger la primera no puede descansar, de manera irreflexiva, en la norma para proteger la segunda. Como ya se ha dicho, este es precisamente el problema que afecta al art. 19 n. ${ }^{\circ} 25$ de la $C P R$ y su remisión al art. 19 n. ${ }^{\circ} 24$.

Haciendo un punto histórico, Ioannis Lianos señala que, en los orígenes del derecho de patentes en Inglaterra, en lugar de utilizarse la palabra 'propiedad' se ocupaba la de 'privilegio', explicando:

"El uso del término 'propiedad' vino más tarde cuando se hizo claro que debería haber algún tipo de justificación de derecho natural para mantener este tipo de monopolio de privilegio en el periodo de laissez-faire que siguió a la era mercantilista" ${ }^{61}$.

El uso de la palabra 'propiedad' respondería a una estrategia de apariencia retórica, pero de finalidad económica, cuyo objetivo era legitimar un control robusto del titular del privilegio sobre el invento. Así, aplicar la fórmula normativa asociada a la propiedad tradicional a la PI tenía por efecto que cualquier pretensión de restringir el alcance del privilegio por parte del regulador debía someterse a un estándar de justificación exigente, so pena de constituir una expropiación.

En este sentido, refiriéndose a la propiedad en términos generales, Enrique Barros caracteriza la fórmula normativa que en general se utiliza para proteger la propiedad tradicional en los siguientes términos:

"La regulación de la propiedad es de las pocas áreas en que el derecho civil actúa con distinciones más bien certeras, entre blanco

${ }^{61}$ Lianos (2010), p. 214. 
y negro, porque los fundamentos pragmáticos y normativos que he referido suponen la necesidad de reducir la incertidumbre a su respecto a la menor medida posible [...] la ley actúa más bien negativamente, como límite a la discreción del propietario [...]”62.

Cabe preguntarse entonces: ¿ La regulación formalista y "negativa" de la propiedad tradicional es pacíficamente aplicable a la PI? Por todo lo ya señalado en los acápites previos, este artículo sostiene que no. De este modo, como notan Ioannis Lianos y Rochelle Dreyfuss:

"The criterion of 'property' is formalistic and does not provide any useful information as to the adequate level of reward and dissemination in order for the scope of the IP right to be optimal"63.

Así las cosas, la regulación constitucional no debe separar el blanco y el negro, sino que debe adoptar un tono gris, reflejando que la PI es una solución de compromiso. Como ya se explicó, a diferencia de la propiedad tradicional, la PI es una herramienta de mercado que trae una promesa concreta: generar creación e innovación que luego pueda ser socialmente aprovechada por todos. En consecuencia, la regulación constitucional debe dar cuenta de esta promesa, reconociendo la función de la PI y sus características normativas propias que posibilitan la ponderación de los intereses en juego, de corto y largo plazo.

Por el contrario, de mantenerse la norma constitucional actual, parasitaria de la propiedad tradicional y opaca respecto a los fines de la PI, se corre el riesgo de que, por ejemplo, una norma de excepción de autorización sea declarada inconstitucional, inaplicable o expropiatoria del referido derecho de PI. Asimismo, la regla de propiedad tradicional (que es por regla general perpetua) puede provocar que el legislador o un órgano administrativo no tome en consideración la duración limitada de los derechos de PI pertenecientes a la primera categoría antes descrita, o sus reglas de excepción de autorización, y establezca restricciones excesivas que terminen por eliminar los incentivos a la innovación y creación.

${ }^{62}$ Barros (2021), p. 231.

${ }^{63}$ Lianos \& Dreyfuss (2013), p. 49. (Traducción libre: "El criterio de la 'propiedad' es formalista y no proporciona ninguna información útil sobre el nivel adecuado de recompensa y difusión para que el alcance del derecho de propiedad intelectual sea óptimo"). 


\section{Propuesta de una nUeVA nORMa CONSTitucional DE PROTECCIÓN A LA PI}

En esta sección se propone un texto de norma constitucional que se hace cargo de las ideas señaladas en las dos secciones previas. Sin embargo, antes de presentar dicho texto, se hará referencia a un método de argumentación basado en la teoría de la justicia de John Rawls para justificar su aceptabilidad social en el contexto de una democracia constitucional moderna.

Sin perjuicio de que la pertinencia de la teoría de la justicia de John Rawls en el debate sobre las instituciones públicas es prácticamente autoevidente en las democracias occidentales, su aplicabilidad en materia de PI ha sido interesantemente tematizada por Giorgio Jackson y Paula Espinoza, en el libro titulado Copia o muerte, una decisión urgente para nuestra supervivencia. Así, los autores sugieren adoptar la figura ralwsiana del "velo de la ignorancia" para distinguir los arreglos justos de los injustos, advirtiendo:

"El anterior ejercicio parece sencillo, pero desafía el lugar desde el que tomamos posición. Nosotros intentamos seguir este camino. Hemos sido tanto autores como copiadores" ${ }^{4}$.

A diferencia de las conclusiones arribadas por los autores mencionados, a continuación se argumentará que la PI es justificable en términos ralwsianos o, al menos, puede serlo en la medida en que sus elementos internos estén configurados de cierta manera. Son estos elementos los que permiten optimizar la relación entre creación y acceso a los bienes protegidos y, así, armonizar la tensión entre autores y copiadores ${ }^{65}$.

\section{Justificación rawlsiana de la norma constitucional que se propone}

Una discusión constitucional es un debate acerca de la estructura básica de la sociedad, es decir, sobre los principales arreglos institucionales que determinan la cooperación social. En consecuencia, al momento de dise-

${ }^{64}$ JaCKSON y EsPinOZa (2019), p. 25.

${ }^{65}$ Este ejercicio ya ha sido emprendido en la literatura académica. Para una opinión que defiende la compatibilidad de la PI con los principios de justicia ralwsianos, véase LIU (2012). Para una opinión contraria, véase MURPHY (2012). Con todo, este último autor parece no considerar el elemento dinámico de los derechos de PI, ya que solo se refiere a las restricciones de acceso generadas en el corto plazo, pero sin reparar en la acumulación de conocimiento accesible en el largo plazo. 
ñar reglas de ese carácter, es imprescindible aplicar un método de argumentación que tenga la pretensión de ser aceptado por todos los actores. Este artículo sostiene que el concepto procedimental de "justicia como imparcialidad" ofrece una alternativa plausible para lograr lo anterior ${ }^{66}$. De lo que se trata entonces es de determinar si la institución de la PI es un arreglo institucional que "personas libres y racionales interesadas en promover sus propios intereses aceptarían en una posición de igualdad" 67 . De una respuesta afirmativa se derivan dos consecuencias:

i) Que la PI debe tener reconocimiento constitucional (pues la $C P R$ define el acuerdo político básico de una sociedad) y, que

ii) Dicho reconocimiento debe transparentar las razones por las cuales la PI es aceptada, a fin de no ser desvirtuada en sus principios por las normas de rango inferior.

En estos términos, la norma constitucional sobre PI debe ser aquella cuyo texto habría sido acordado en un escenario hipotético de "posición original" bajo un "velo de la ignorancia" ${ }^{6}$. Esto significa que los intervinientes en esa discusión desconocen el lugar que ocuparán en la sociedad, su suerte en la distribución de las ventajas y talentos e, incluso, la generación a la cual pertenecerán ${ }^{69}$. Una norma aceptada en estas condiciones, desprejuiciadas e igualitarias, tendría entonces la capacidad de ser reconocida como legítima por todos, dado que no se encontraría comprometida con el interés de ningún sector particular de la sociedad (esto es, sería una norma imparcial).

De este modo, en virtud del "velo de la ignorancia", los intervinientes, en principio, pueden autocomprenderse como ciudadanos y consumidores, trabajadores y dueños de capital, y, como sugieren Giorgio Jackson y

${ }^{66}$ La idea de justicia como imparcialidad desarrollada por John Rawls es una concepción de la justicia que se funda en la tradición contractualista desarrollada por John Locke, JeanJacques Rousseau e Immanuel Kant. Su objetivo es determinar cuáles son los principios de justicia que serían acordados en un escenario de negociación (o "elección inicial”) de carácter hipotético e imparcial (llamado "posición original"), es decir, un escenario ciego a la suerte, estatus y talentos de cada persona (por el llamado "velo de la ignorancia"). Se trata de un concepto de justicia de naturaleza procedimental y no material, ya que el énfasis está en las condiciones de la negociación y no en su resultado. Con todo, cabe advertir que dichas condiciones de negociación no son moralmente neutras, sino que tienen la pretensión de reflejar la igualdad moral de todos los seres humanos. RAwLS (1971), pp. 24-33.

${ }^{67}$ Op. cit., p. 24.

${ }^{68}$ Op. cit., pp. 135-140.

${ }^{69}$ Cabe notar que la justicia intergeneracional es congruente con el análisis dinámico de la PI, que comprende la PI como una herramienta para incrementar, en el largo plazo, la acumulación de conocimiento artístico y tecnológico disponible en una sociedad. De este modo, las restricciones de acceso a un bien protegido en el corto plazo pueden resultar justas, pues tendrán como resultado una liberación de dicho conocimiento para las próximas generaciones. 
Paula Espinoza, como creadores-autores y receptores-copiadores del conocimiento ${ }^{70}$. En efecto, cualquiera sea el plan de vida de las personas que participan en la posición original, es muy probable que para su ejecución se requiera acceder a algún grado de conocimiento (entendiendo por tal los bienes tecnológicos y artísticos), ya sea para su desarrollo intelectual o sus emprendimientos comerciales. En términos ralwsianos, estos son los "bienes primarios" en juego ${ }^{71}$.

Asumiendo que los intervinientes son racionales y que normalmente preferirán tener más cantidad del bien que menos ${ }^{72}$, la norma constitucional a acordar será aquella que optimice la creación y distribución del conocimiento. Esto significa que la norma debe compatibilizar de la mejor manera posible los intereses del rol innovador, que procura generar conocimiento, con los intereses del rol receptor-copiador, que espera recibir y utilizar el conocimiento ya creado. Cabe notar que estas categorías no son alternativas sino conjuntas. Desde luego, todo innovador es siempre receptor de conocimiento ya creado y todo receptor es, potencialmente, un agente innovador.

Este método de razonamiento permite descartar un esquema normativo que, con miras a posibilitar un acceso igualitario al conocimiento, elimine la PI. Este arreglo no sería elegido por los intervinientes en la posición original, dado que generaría un nivel subóptimo de conocimiento en la sociedad precisamente por la falta de incentivos a la creación. Así, el esquema en comento, con miras a maximizar la distribución, sacrifica la creación. Como advierte Robert Nozick respecto a patrones de asignación que solo enfatizan el rol distributivo:

"If somehow the size of the pie wasn't fixed, and it was realized that pursuing an equal distribution somehow would lead to a smaller

${ }^{70}$ Como provocativamente sostiene Jeremy Waldron: "Clearly our concept of the author and this concept of the copier are two sides of the same coin. If we think of an author as having a natural right to profit from his work, then we will think of the copier as some sort of thief; whereas if we think of the author as beneficiary of a statutory monopoly, it may be easier to see the copier as an embodiment of free enterprise values". WALDRON (1992), p. 842. (Traducción libre: "Claramente nuestro concepto de autor y este concepto de copiador son dos caras de la misma moneda. Si pensamos en el autor como alguien que tiene un derecho natural a obtener ganancias de su trabajo, entonces pensaremos en el copiador como una especie de ladrón; en cambio si pensamos en el autor como beneficiario de un régimen de monopolio, podría ser más fácil ver al copiador como una encarnación de la libre empresa").

${ }^{71}$ Los bienes primaros son aquellas cosas "que se presume que todo ser racional desea”, y que a grandes rasgos se dividen en derechos, libertades, oportunidades, ingreso y riqueza. RAwLS (1971), p. 69.

${ }^{72}$ Op. cit., p. 140. 
total pie than otherwise might occur, the people might well agree to an unequal distribution which raised the size of the least share" ${ }^{73}$.

De la misma forma, se descartaría un esquema normativo que, con miras a generar un alto nivel de conocimiento, fije derechos muy fuertes de PI, es decir, derechos de muy larga extensión en cuanto a su objeto y de muy larga duración en cuanto a su duración. Este arreglo no sería elegido, ya que excluiría del acceso al conocimiento a la mayoría de los miembros de la sociedad, quedando este solo disponible para un reducido grupo de beneficiados con el privilegio estatal. Al respecto, Hanoch Dagan explica:

"The scope and the content of authors' rights should be carefully delineated in order to avoid the unfortunate predicament of society paying too much for its creative resources or undermining future creativity, which inevitably engages, invokes, and is inspired by preexisting cultural raw materials [...] copyright must never aim only at maximizing the size of the creative pie without looking at its distribution" 74 .

En consecuencia, el esquema normativo que se elegiría en una posición original sería la de derechos de PI "moderados". Si bien estos derechos generan inequidades, estas irían en el mediano o largo plazo en beneficio de la sociedad. Esto satisface el "principio de la diferencia" ralwsiano, conforme al cual las desigualdades sociales y económicas solo son aceptables en la medida en que ellas resulten en beneficio de todos y, especialmente, de los más desaventajados ${ }^{75}$. En este punto, cabe destacar

${ }^{73}$ Nozick (1974), p. 198. (Traducción libre: "Si de alguna manera el tamaño del pastel no estuviese fijado, y se comprendiera que perseguir una distribución equitativa de alguna manera conduciría a un pastel total más pequeño del que de otro modo podría haber existido, las personas bien podrían acordar en una distribución inequitativa del pastel que incrementara el tamaño de la menor porción”).

${ }^{74}$ Dagan (2011), p. 51. (Traducción libre: "El contenido y alcance de los derechos de autor debe ser cuidadosamente delimitado con el fin de evitar la desafortunada situación de que la sociedad pague demasiado por sus recursos creativos o socave la creatividad futura, que inevitablemente involucra, invoca y está inspirada en materias primas culturales preexistentes [...] los derechos de autor nunca deben apuntar solo a maximizar el tamaño del pastel creativo sin tener en cuenta su distribución”).

${ }^{75}$ Rawls (1971), pp. 68-69. En el mismo sentido, Deming Liu, sobre la base de las ideas de Peter Drahos, sostiene: "The copyright scheme may be allowed, hence such primary goods as information are allowed to be owned and controlled by some to the exclusion of others if the arrangement works to the best of the least advantaged". LIU (2012), p. 612. (Traducción libre: "El esquema de derechos de autor puede estar permitido, por lo tanto, se permite que algunos bienes primarios como la información sean apropiados y 
que John Rawls considera consistente con el principio de la diferencia sostener que las mayores expectativas permitidas a los empresarios "actúan como incentivos que harán más eficaz el proceso económico, más rápida la introducción de innovaciones" ${ }^{\text {" }}$. Como bien sugiere a este respecto Deming Liu: "Rawls believes that the talented should earn premiums, but the premiums are used to contribute to the welfare of the least well off"

Corresponde preguntarse entonces: ¿̇en qué sentido deberían ser "moderados" los derechos de PI que serían diseñados en una posición original? La respuesta es que ellos son moderados en la medida en que incorporan, en su propia estructura, elementos que delimitan su capacidad "apropiativa" de la información, pero sin anular su aptitud para generar incentivos a la creación e innovación.

Estos elementos son:

i) Su duración, que no puede ser demasiado larga en relación con las dinámicas del desarrollo tecnológico y artístico de la sociedad ${ }^{78}$,

ii) Su esfera de aplicabilidad, que no puede alcanzar ciertas áreas del conocimiento (para evitar su comodificación) ${ }^{79}$,

iii) Su extensión, que al menos en materia de patentes (en sentido amplio $)^{80}$ debería ser congruente con el grado de innovación y

iv) Sus mecanismos internos que permitan, en casos concretos, balancear intereses particulares y generales (entre otros, excepciones de autorización y doctrina del "agotamiento" del derecho).

controlados por algunos con la exclusión de otros, si el arreglo funciona para lo mejor de los menos aventajados").

${ }^{76}$ RAWLS (1971), p. 83.

${ }^{77}$ LiU (2012), p. 609. (Traducción libre: "Rawls cree que los talentosos deben ganar premiums, pero los premiums se utilizan para contribuir al bienestar de los menos aventajados").

${ }^{78}$ En materia de patentes, Meir Pugatch señala: "The optimum patent term of protection is also highly disputable. A longer patent term increases the incentive to invent but also prolongs the restriction on the use of existing knowledge. Therefore, not only is it difficult to establish one patent terms optimal to society, but it is also likely that different inventions require different terms of protection". PugATch (2005), p. 434. (Traducción libre: "El tiempo de duración óptimo de una patente es también muy discutible. Un plazo de patente más largo aumenta el incentivo para inventar, pero también prolonga la restricción del uso de los conocimientos existentes. Por lo tanto, no solo es difícil establecer los plazos de duración óptimos de una patente para la sociedad, sino que también es probable que diferentes invenciones requieran diferentes términos de protección”).

${ }^{79}$ A modo de ilustración, conforme al art. 37 letra c de la Ley n. ${ }^{\circ}$ 19039, las "actividades puramente mentales" no pueden ser patentadas. Asimismo, de acuerdo con el art. 20 letra a) de la misma ley, las banderas o emblemas de los países no pueden ser registrados como marcas comerciales.

${ }^{80}$ Por patentes se comprenden también los modelos de utilidad, y los dibujos y diseños industriales (véase nota al pie n. ${ }^{\circ} 59$ ). 
Es importante notar que todos estos elementos no son exógenos y, en este sentido, "expropiatorios" de los derechos de PI, sino que son parte inmanente de ellos.

Más concretamente, respecto a la duración de los derechos de PI es admisible pensar que esta no debería exceder los límites establecidos en los tratados internacionales suscritos y ratificados por Chile (por ejemplo, ADPIC) ${ }^{81}$. En cuanto a su esfera de aplicabilidad, es razonable excluir aquellas áreas del conocimiento que deben quedar en el dominio público en atención a su esencialidad en la interacción social, tales como ciertos aspectos de la naturaleza, las teorías científicas o los métodos económicos ${ }^{82}$. En cuanto a su extensión, los derechos de PI no pueden cubrir las ideas en su totalidad, sino solo una expresión de ellas (en el caso de los derechos de autor $)^{83}$ o una dimensión específica de ellas (en el caso de las patentes), quedando siempre la posibilidad de que otro agente pueda arribar a la misma idea, aunque a través de otros caminos creativos. Por último, en cuanto a los mecanismos internos de balance, estos deben consistir en posibilidades de uso no autorizado que tengan un carácter incidental, no comercial o investigativo (por ejemplo, posibilitando la actividad creativa derivada) ${ }^{84}$.

${ }^{81}$ En este sentido cabe tener, además, presente la norma contenida en el inciso final del art. 135 de la actual $C P R$, conforme al cual el texto de la nueva Constitución debe respetar "los tratados internacionales ratificados por Chile y que se encuentren vigentes" (entre ellos el ADPIC, el Convenio de Berna para la Protección de Obras Literarias y Artísticas, el Convenio de París para la Protección de la Propiedad Industrial y la Convención de Roma sobre la Protección de los Artistas Intérpretes o Ejecutantes, los Productores de Fonogramas y los Organismos de Radiodifusión). En caso de existir normas en la nueva Constitución que contradigan lo dispuesto en los tratados, estas serían jurídicamente válidas, toda vez que las materias reguladas en ellos son de naturaleza comercial (y no de derechos humanos), de modo que malamente podrían tener un rango supra constitucional. Sin embargo, la contradicción normativa en comento sí podría comprometer la responsabilidad civil del Estado ante otros Estados o, bien, ante inversionistas extranjeros, exigible a través de los mecanismos de solución de controversias dispuestos en los mismos tratados. Todo lo anterior, sin perjuicio de las normas que pueda establecer la nueva Constitución en materia de tratados internacionales.

${ }^{82}$ En este sentido, véase art. 37 de la Ley n. ${ }^{\circ} 19039$.

${ }^{83}$ A modo de ilustración, la Corte Suprema de Estados Unidos ha declarado en una sentencia reciente que los programas computacionales se diferencian de otras obras protegidas por copyright porque los programas computacionales siempre sirven a un propósito funcional. Por ello, arguye dicha Corte, el fair use tiene un importante papel que representar para mantener el monopolio de copyright conferido a programas computacionales dentro de sus límites legales. Google LLC v. Oracle America, Inc. (2021), p. 2.

${ }^{84}$ En este sentido, como reglas de excepción de autorización en materia de derechos de autor, se puede mencionar el art. 17 Q de la Ley n. ${ }^{\circ} 17336$, de acuerdo con el cual: "Es lícito el uso incidental y excepcional de una obra protegida con el propósito de crítica, comentario, caricatura, enseñanza, interés académico o de investigación, siempre que dicha utilización no constituya una explotación encubierta de la obra protegida". Asimismo, se puede indicar el art. $71 \tilde{\mathrm{N}}$ de la misma ley que, respecto a programas computacionales, 
A mayor abundamiento, los derechos de PI moderados no solo resultan justos en los términos ya señalados, sino que, además, promueven la eficiencia y desarrollo tecnológico. Al respecto, Margaret Radin arguye que, dado que las empresas necesitan acceso al conocimiento generado por otras empresas para desarrollar sus propias innovaciones, ellas tienen un incentivo racional para apoyar una regulación que les permita acceder a ciertas porciones de los contenidos desarrollados por otras empresas, de modo recíproco ${ }^{85}$. En este sentido, se debe tener en consideración que las tecnologías (y también el arte) surgen de un proceso evolutivo de combinación (combinatorial evolution). Como explica Arthur Brien en su obra La naturaleza de la tecnología, las tecnologías novedosas son creadas a partir de "bloques de construcción" (building blocks) que son en sí mismos tecnologías y que, a su vez, se convierten en potenciales bloques de construcción para el desarrollo de nuevas tecnologías, y así sucesivamente ${ }^{86}$. En consecuencia, el avance tecnológico requiere que la PI contemple mecanismos eficaces de acceso, que permitan realizar ejercicios de combinación y construcción sobre lo ya existente.

Teniendo presente todas estas consideraciones, cabe ahora referirse al texto de una posible norma constitucional congruente con ellas.

\section{Propuesta de texto de nueva norma constitucional}

La norma que se propone es la siguiente:

"Esta Constitución asegura a todas las personas los derechos de propiedad intelectual, de propiedad industrial y los derechos sobre variedades vegetales que, en conformidad a la ley, recaigan sobre las creaciones artísticas, innovaciones tecnológicas, signos distintivos y variedades vegetales, respectivamente.

El modo de adquisición de los derechos indicados en el inciso anterior, su objeto, su duración, sus atributos y sus mecanismos

permite actividades adaptativas, de ingeniería inversa e investigativas. Por otro lado, en materia de patentes de invención, se encuentra el nuevo inciso final del art. 49 de la Ley n. ${ }^{\circ} 19039$ (incorporado por la Ley n. ${ }^{\circ} 21355$ ), conforme al cual el derecho de patente no se extiende a "actos realizados privadamente y sin motivos comerciales" o a los "actos realizados por motivos exclusivamente experimentales". Esta última norma sería, además, aplicable a los modelos de utilidad, diseños industriales, dibujos industriales y esquemas de trazado o topografías de circuitos integrados (de acuerdos con las remisiones de los arts. 55, 63 y 83 , respectivamente. Por último, en materia de variedades vegetales se identifica el art. $5^{\circ}$ de la Ley n..$^{\circ} 19342$, que autoriza a terceros a emplear una variedad vegetal protegida para crear una nueva variedad, sin requerir autorización.

${ }^{85}$ Radin (2004), pp. 180-181.

${ }^{86}$ BRIAN (2009), p. 190. 
de tutela efectiva y oportuna, serán establecidos y regulados en la ley. Dicha regulación debe contribuir tanto a la promoción de la creación artística y a la innovación tecnológica, como a su transferencia, difusión y acceso a lo largo del tiempo, propendiendo al beneficio mutuo de creadores, innovadores, usuarios y beneficiarios del conocimiento protegido mediante dichos derechos.

Asimismo, y solo por razones de interés general, la ley deberá establecer procedimientos de concesión de licencias no voluntarias de los derechos de propiedad intelectual, industrial y de variedades vegetales, las cuales deben posibilitar un uso racional, proporcionado, por un tiempo previamente delimitado y compatible con la explotación comercial de dichos derechos. Estos procedimientos deberán garantizar una justa compensación a su titular, así como el derecho de aquél de reclamar judicialmente en caso de contravenirse cualquiera de los estándares previamente indicados.

El Estado y sus órganos deberán implementar regulaciones y políticas para contribuir a las actividades de investigación y desarrollo, transferencia tecnológica y difusión del dominio público, propendiendo al desarrollo progresivo de la tecnología, las ciencias y la economía del país".

Como se observa, el texto propuesto se refiere únicamente a la PI y no a la propiedad tradicional. En consecuencia, se mantiene el tratamiento diferenciado que realiza la $C P R$ actual y que separa ambas instituciones (art. 19 n. ${ }^{\circ} 24$ y art. 19 n. ${ }^{\circ}$ 25). Sin embargo, salta a la vista que el texto de la norma propuesta ya no es opaco o "parco", sino que asume un carácter programático y congruente con los fines de la PI. A continuación, se destacan los elementos principales de la norma propuesta.

En primer lugar, la norma propuesta no separa, como sugiere Enrique Barros, el blanco del negro, sino que es de tono gris. Ella refleja que la PI es una solución de compromiso, atravesada por un equilibrio entre creación y acceso al conocimiento. En este sentido, es conveniente que la norma tenga un tono gris con el fin de brindar al legislador un marco jurídico que tenga la plasticidad suficiente para que, respecto a cada área del conocimiento, dicho equilibrio sea actualizado en atención a la dinámica del desarrollo tecnológico y artístico de la sociedad. Lo mismo respecto al adjudicador, que siembre deberá interpretar la ley conforme a la $C P R$ en virtud del principio de supremacía constitucional.

En segundo lugar, la norma propuesta no contiene una regla similar a la del párrafo $4 .^{\circ}$ del art. $19 \mathrm{n} .^{\circ} 25$ de la actual $C P R$. En efecto, no se incluye una remisión a la norma sobre propiedad tradicional en materia de "atributos", "función social" o "expropiación”. Respecto a los atributos, 
en el párrafo $2 .^{\circ}$ de la norma se indica que estos deben ser establecidos en la ley, pudiendo así variar para cada derecho de PI. En relación con la función social, esta se encuentra expresada en los párrafos $2 .^{\circ}$ y $3 .^{\circ}$ del texto propuesto, en congruencia con los fines específicos de la PI (i.e., promover tanto la creación de conocimiento como el acceso a él, a lo largo del tiempo). Además, la institución de la expropiación se reemplaza por el de la licencia no voluntaria fundada en el interés general, por ser esta última fórmula más dinámica e idónea en razón de la naturaleza inmaterial de los derechos de PI. Además, la institución de la licencia no voluntaria resultaría aplicable a las patentes (en sentido amplio), variedades vegetales y derechos de autor ${ }^{87}$, pero no a los derechos que recaen sobre signos distintivos (pues como se explicó en la sección III, estos no recaen sobre los bienes artísticos o tecnológicos, sino solo sobre los signos).

En tercer lugar, la norma establece en su párrafo final un deber para el Estado (y sus órganos) de contribuir a las actividades de investigación y desarrollo, transferencia tecnológica y difusión del dominio público (y de forma progresiva). Esto, pues, si bien la PI es una herramienta propia de una economía de mercado, para optimizar su utilización se requiere la colaboración de organismos estatales, ya sea para reducir los riesgos asociados a la innovación que la PI no alcanza a recompensar ${ }^{88} \mathrm{o}$, bien, 286 maximizar la diseminación del conocimiento asociado a los bienes tecnológicos o artísticos protegidos, tanto a escala empresarial como social ${ }^{89}$. En este sentido, se ha reconocido que el Estado puede cumplir un papel importante para dar el "punta pie inicial" necesario para configurar nuevos mercados o inducir la inversión privada en innovación ${ }^{90}$. En estos términos, el CTICI ha señalado:

"Inicialmente el Ecosistema [de innovación] precisa de un impulso estatal muy marcado. Luego, una vez que este alcance una masa crítica, las herramientas científico-tecnológicas disponibles servirán de apoyo al sector privado para que aumente la densidad tecnoló-

${ }^{87}$ En la actualidad, en materia de variedades vegetales la licencia no voluntaria solo se puede gatillar por razones de abuso monopólico en la explotación comercial (art. 7. ${ }^{\circ}$ de la Ley n. ${ }^{\circ} 19342$ ), pero no por otras razones de interés general. Por otro lado, en materia de derechos de autor, no se reconoce la institución de licencias no voluntarias, sino solo la de expropiación (art. 11 letra 'e' de la Ley n. ${ }^{\circ}$ 17336).

${ }^{88}$ ARrow (1962), pp. 619 y 634-624.

${ }^{89}$ Como señala un reciente informe del CTICI: "El Estado tiene la misión de propiciar un ecosistema que dé fluidez a la transmisión de conocimiento, a pesar que aquellos que participen no puedan anticipar el valor que surgirá de ella". Consejo NaCiOnal DE Ciencia, Tecnología, Conocimiento e Innovación para el Desarrollo (2021), p. 35.

${ }^{90}$ Mazzucato (2013), p. 9. 
gica de su quehacer. Posteriormente, y una vez que el sector privado, a su vez, alcance una masa crítica apropiada, el proceso se retroalimenta virtuosamente entre ambos, y el porcentaje de participación privada en el Ecosistema tiende a transformarse en predominante" $"$.

Como se observa el texto propuesto logra superar la limitada concepción de la PI expresada en el actual art. 19 n. ${ }^{\circ} 25$ de la $C P R$, cuyo único objetivo era, en las ya referidas palabras de Alejandro Silva Bascuñán, "que se entienda que lo que se quiere proteger es la propiedad". En efecto, el texto propuesto distingue las finalidades propias de la PI sin remitirse a la propiedad tradicional, y en términos tales que pueda ser aceptada bajo los principios rawlsianos de justicia como imparcialidad.

A mayor abundamiento, es pertinente notar que la norma propuesta encuentra resonancias directas con la sección $8^{\mathrm{a}}$ del art. $1 .^{\circ}$ de la Constitución de Estados Unidos y el art. $7^{\circ}$ del ADPIC. En cuando a la sección $8^{\mathrm{a}} \mathrm{del}$ art. $1 .^{\circ}$ de la Constitución de Estados Unidos, esta establece:

"[The United States Congress shall have power] To promote the progress of science and useful arts, by securing for limited times to authors and inventors the exclusive right to their respective writings and discoveries" $"$.

Esta norma constitucional, aunque concisa, revela el papel instrumental o teleológico de la PI, en tanto herramienta adscrita a un fin: promover el progreso científico y las artes. En una línea similar, aunque mostrando un carácter aún más programático, se encuentra el art. $7^{\circ}$ del ADPIC, que bajo el encabezado "Objetivos" establece:

"La protección y la observancia de los derechos de propiedad intelectual deberán contribuir a la promoción de la innovación tecnológica y a la transferencia y difusión de la tecnología, en beneficio recíproco de los productores y de los usuarios de conocimientos tecnológicos y de modo que favorezcan el bienestar social y económico y el equilibrio de derechos y obligaciones".

${ }^{91}$ Consejo Nacional de Ciencia, Tecnología, Conocimiento e Innovación para el Desarkollo (2021), p. 46.

${ }^{92}$ Traducción libre: “[El Congreso de los Estados Unidos tendrá el poder] para promover el progreso de la ciencia y las artes útiles, por medio del aseguramiento por tiempo limitado a los autores e inventores de los derechos exclusivos a sus respectivos escritos y descubrimientos". 
Henning Grosse Ruse-Khan señala que esta norma genera una mediación entre consideraciones económicas y sociales que implica un espacio en el ámbito doméstico (es decir, para el Estado miembro) para encontrar el balance más apropiado ${ }^{93}$. Este es precisamente el sentido del carácter programático del texto constitucional propuesto más atrás ${ }^{94}$. Además, el art. $7 .^{\circ}$ del ADPIC da buena cuenta de la justificación ralwsiana de la PI, en la medida en que enlaza la fundamentación de su protección con el beneficio de los usuarios y el bienestar social, de modo que sea reconocida como una regla justa, incluso por quienes no tienen acceso a los bienes protegidos por la PI en un momento determinado ${ }^{95}$.

En este punto, y asumiendo ahora una perspectiva propiamente internacional, resulta pertinente detenerse en la cuestión acerca de si la adopción de normas de protección de la PI cumple o no con el principio de la diferencia ralwsiano en términos de si ella, en general, ha beneficiado o perjudicado a los países en vías de desarrollo (o si, en cambio, solo ha beneficiado a los países desarrollados, es decir, a los más aventajados en el plano global $)^{96}$. Esto pues, si bien la capacidad de un sistema nacional de protección de la PI para beneficiar a los más desaventajados depende de sus elementos normativos propios, el hecho de que el sistema internacional

${ }^{93}$ Grosse (2018), pp. 27-28.

${ }^{94}$ En este sentido, la norma constitucional propuesta en este artículo tiene la virtud de comprender la PI como un nodo o lugar de intersección de distintos intereses económicos y sociales. Se trataría en consecuencia de lo que, en relación con el derecho real de conservación, Jaime Ubilla llama "derecho reflexivo". Esto es, un derecho que no envuelve ni una contradicción a la visión autonomista del derecho privado, ni involucra una instrumentalización del mismo, sino que "justamente busca facilitar la integración de distintas esferas sociales por medio de la auto-regulación de los sujetos y esferas reguladas". Ubilla (2016), p. 159.

${ }^{95}$ Esta idea está en línea con el párrafo 4 de la Declaración de Doha relativa al acuerdo ADPIC y la salud pública, sosteniendo la compatibilidad de dicho tratado y sus instituciones (particularmente sus arts. 30 y 31 sobre licencias no voluntarias) con el acceso a los medicamentos: "Convenimos en que el Acuerdo sobre los ADPIC no impide ni deberá impedir que los Miembros adopten medidas para proteger la salud pública. En consecuencia, al tiempo que reiteramos nuestro compromiso con el Acuerdo sobre los ADPIC, afirmamos que dicho Acuerdo puede y deberá ser interpretado y aplicado de una manera que apoye el derecho de los Miembros de la OMC de proteger la salud pública y, en particular, de promover el acceso a los medicamentos para todos". Disponible en www.wto.org/spanish/ thewto_s/minist_s/min01_s/mindecl_trips_s.htm [fecha de consulta: 2 de julio de 2021].

${ }^{96}$ Por "normas de protección de la PI" se deben entender el conjunto de las regulaciones nacionales (entre otros, ley nacional de patentes o de derechos de autor) e internacionales, sean estas últimas bilaterales (vr. gr., capítulos de PI en tratados de libre comercio) o multilaterales (por ejemplo, ADPIC). Es pertinente notar que las regulaciones nacionales de PI también tienen un impacto internacional, pues codeterminan tanto la cantidad y naturaleza de la inversión extranjera en el país así como la cantidad y naturaleza de sus exportaciones e importaciones. 
de protección de la PI, generalmente considerado, pueda producir ese efecto entre países con distinto nivel de desarrollo, constituye un elemento indicativo de que la PI puede generar un efecto similar al interior de un país determinado.

En este sentido, si bien las causas del desarrollo económico y tecnológico en una sociedad son múltiples (por ejemplo, nivel de educación o profundidad del sector financiero), como regla general puede afirmarse que la protección de la PI impacta positivamente en dicho desarrollo. A este respecto, Stephen Haber señala que, en la actualidad y como patrón general, se puede observar que no existen países ricos con derechos de patente débiles ni países pobres con derechos de patente fuertes ${ }^{97}$.

Sin embargo, el mismo autor advierte que la relación entre innovación y protección de las patentes no es lineal, sino que tiene un "efecto de umbral" ${ }^{\prime}$. Este consiste en que el impacto positivo de las patentes se produce una vez que la sociedad en cuestión ya ha alcanzado cierto nivel de desarrollo, a saber: en materia de educación, avance científico, movilidad de capital y reglas de competencia que evitan el abuso monopólico. Todos estos son factores de desarrollo que permite aprovechar de mejor manera la institución de las patentes y de los derechos de PI en general. De este modo, la PI, por sí sola, puede reportar menos beneficios para el desarrollo de los países, especialmente para los menos desarrollados (que se verían impedidos de acudir a mecanismos informales de transferencia tecnológica, como la simple imitación o la ingeniería reversa), en comparación con los beneficios que ella aporta cuando se encuentra complementada por los factores de desarrollo ya indicados ${ }^{99}$.

En la misma línea, Joseph Straus sugiere que el ADPIC, en tanto pilar del entramado de tratados multilaterales de la Organización Mundial de Comercio $^{100}$, ha ido en beneficio de los países en desarrollo ${ }^{101}$. Dicho autor

${ }^{97}$ Haber (2016), p. 815.

${ }^{98}$ Op. cit., p. 830.

${ }^{99}$ Para un estudio acerca de la manera en que los estándares de protección de la PI fijados en el ADPIC benefician a los países desarrollados, a los países en vías de desarrollo y a los países menos desarrollados, véase PARK \& LipPOLDT (2008). Sobre la base de un análisis empírico, estos autores sugieren que los derechos de PI estimulan la transferencia tecnológica (en particular la de bienes intensivos en tecnologías) y, además, pueden estimular directamente la innovación local. Asimismo, constatan que, si bien estos efectos se verifican con mayor claridad en países desarrollados, también se pueden verificar en los países en vías de desarrollo e, incluso, en aquellos menos desarrollados, aunque en un menor grado.

${ }^{100}$ Como parte de este entramado se debe mencionar el GATT y el Acuerdo General sobre el Comercio de Servicios. Ambos instrumentos establecen obligaciones de igualdad de trato y no discriminación respecto al origen nacional de los productos o servicios que se exportan e importan internacionalmente.

${ }^{101}$ STraus (2007). 
destaca en particular los casos de China e India, que a medida que fueron abriendo sus economías a la inversión extranjera y, de forma simultánea, modernizando su legislación de PI, sus índices de crecimiento y desarrollo tecnológico fueron aumentando ${ }^{102}$. De hecho, si bien anteriormente ambos países se caracterizaban por incurrir en prácticas informales de transferencia tecnológica, en la actualidad encabezan el ranking internacional de naciones con más solicitudes y registros de patentes, al igual que Corea del Sur ${ }^{103}$.

A mayor abundamiento, Hiroko Yamane destaca el impacto positivo que la protección de la PI genera en la inversión extranjera de contenido tecnológico y con valor agregado (en términos de investigación y desarrollo), afirmando que las empresas extranjeras suelen ofrecer un nivel de tecnología acorde con el grado de protección de la PI que se adopte en el país en que se invertirá ${ }^{104}$. Esta idea es consistente con lo observado por Stephen Haber, en cuanto a que la protección de la PI permite a las empresas desarrollar y comercializar no solo tecnologías de conocimiento tácito, sino, también, de conocimiento codificado (i.e., tecnologías susceptibles a la ingeniería reversa $)^{105}$, pues la PI reduce la transferencia tecnológica informal, incentivando en cambio la transferencia formal (por ejemplo, disclousure de conocimiento técnico para registrar derechos de PI, 290 contratos de licencia o joint-ventures de base tecnológica entre empresas locales y extranjeras). Lo anterior hace posible que un país en desarrollo pueda recibir transferencia tecnológica de mayor complejidad y de manera sostenible en el tiempo. En este sentido, Hiroko Yamane acude a la distinción entre un modelo estático y uno dinámico para examinar el beneficio de la protección de la PI en los países en desarrollo, sugiriendo:

${ }^{102}$ Straus (2007), pp. 50-52.

${ }^{103}$ De acuerdo con la base de datos de la Organización Mundial de la Propiedad Intelectual, desde el año 2000 en adelante la curva de crecimiento de solicitudes de patentes presentadas por nacionales y extranjeros en China, India y Corea del Sur se ha elevado de forma notoria. Así, a modo de ilustración, en el año 2000 el número aproximado de solicitudes presentadas en India fue de cinco mil (de las cuales dos mil doscientas fueron presentadas por residentes), en China fue de cincuenta mil (de las cuales veinticinco mil fueron presentadas por residentes) y en Corea del Sur fue de cien mil (de las cuales setenta y tres mil fueron presentadas por residentes). En cambio, en el año 2019, el número aproximado de solicitudes presentadas en India fue 50.000 (diecinueve mil cuatrocientas presentadas por residentes), en China fue de un millón cuatrocientas mil (un millón doscientas mil presentadas por residentes) y en Corea del Sur fue de doscientas veinte mil (ciento setenta y un mil presentadas por residentes). Estas estadísticas se pueden consultar en el data center virtual de la Organización Mundial de la Propiedad Intelectual, disponible en www3.wipo.int/ipstats/index.htm [fecha de consulta: 20 de agosto 2021].

${ }^{104}$ YAMANE (2011), p. 57.

${ }^{105}$ Haber (2016), p. 820. 
"With a static model, the costs of raising the standards of patent protection are captured by the transfers of income between countries. The United States would be by far the major beneficiary from this model. With a dynamic model, however, these transfers are offset by the greater incentives that exist to innovate [...] Countries with scientific and technological skills and infrastructure may offset short-run losses with long-run gains from intensified R\&D activities, by taking advantage of a superior set of technologies [...]"106.

Por otro lado, desde una visión más crítica acerca de la relación entre la PI y los países en desarrollo, Ha-Joon Chang observa que el problema de aumentar los estándares de protección de la PI en los países menos desarrollados o en vías de desarrollo, es que muchas veces estos países no tienen las capacidades de investigación ni productivas suficientes para tomar ventaja de dicho aumento de protección ${ }^{107}$. De este modo, el autor en comento sostiene que el sistema internacional de protección de la PI, representado en el ADPIC, debe ser reformado de forma tal que permita a los países en vías de desarrollo otorgar una protección más débil a los derechos de PI (por ejemplo, menor duración de patentes o un sistema de licencias no voluntarias más flexible ${ }^{108}$. Sin embargo, lo relevante es notar que Ha-Joon Chang no aboga por eliminar la protección de la PI, sino por calibrarla, señalando de esta manera:

"The real question is not whether IPR protection is good or bad in abstract. It is how we get the balance right between the need to encourage people to produce new knowledge and the need to ensure that the costs from the resulting monopoly do not exceed the benefits that the new knowledge brings about" ${ }^{109}$.

${ }^{106}$ Yamane (2011), p. 58. (Traducción libre: "Con un modelo estático, los costos de elevar los estándares de protección de patentes son capturados por las transferencias de ingresos entre países. Estados Unidos sería por lejos el mayor beneficiario de este modelo. Sin embargo, con un modelo dinámico estas transferencias se compensan por los mayores incentivos que existen para innovar [...]. Los países con capacidades e infraestructura tecnológica pueden compensar las pérdidas a corto plazo con ganancias a largo plazo provenientes de la intensificación de las actividades de $\mathrm{I}+\mathrm{D}$, aprovechando un conjunto superior de tecnologías [...]").

${ }^{107}$ Chang (2008), pp. 141.142.

108 Op. cit., p. 143.

${ }^{109}$ Ibid. (Traducción libre: "Entonces, la verdadera pregunta no es si los derechos de propiedad intelectual son buenos o malos en abstracto. Es cómo logramos el balance adecuado entre la necesidad de alentar a las personas para que produzcan nuevo conocimiento y la necesidad de asegurar que los costos del monopolio resultante no excedan a los beneficios que trae consigo el nuevo conocimiento"). 
De este modo, se puede afirmar que la protección internacional de la PI sí puede beneficiar a los países menos desarrollados, especialmente en la medida en que ella sea complementada por otros factores normativos, económicos y sociales que hagan posible un mayor aprovechamiento de la PI. Lo anterior no obsta a que, como sugiere Ha-Joon Chang, la realización de ciertos ajustes en el sistema internacional de protección de la PI para permitir la adopción de estándares diferenciados de protección que sean congruentes con el grado de desarrollo de cada país, podría optimizar el balance entre creación y acceso al conocimiento (en los mismos términos que plantea el art..$^{\circ}$ del ADPIC, previamente citado).

Ahora bien, volviendo al plano nacional y a la discusión constitucional que motiva el presente artículo, de lo que se trata es de diseñar un sistema interno de protección de la PI que permita balancear, de forma óptima, la creación de nuevo conocimiento con su posterior acceso o distribución. En efecto, de esta optimización depende el cumplimiento del principio de diferencia rawlsiano. En estos términos, la norma constitucional propuesta en esta sección, a diferencia de la norma constitucional actual, es un marco jurídico que está diseñado para lograr dicho balance de acuerdo con el estado de desarrollo de Chile, tomando en consideración sus necesidades económicas y sociales.

\section{PotenCial DESEMPeÑo DE LA NORMA PROPUESTA}

Una norma constitucional como la propuesta tiene la aptitud de generar efectos en el ámbito legislativo, administrativo y judicial. A continuación, y solo a modo de ilustración, se mencionarán algunos de ellos.

\section{En materia legislativa y administrativa}

A diferencia del actual art. 19 n. ${ }^{\circ} 25$ de la $C P R$, la norma constitucional propuesta revela una concepción integral del fenómeno de la PI en el ordenamiento jurídico, económico y social. Es decir, no se agota en constatar la PI como un derecho de propiedad, sino que, además, consagra sus fines (i.e., contribuir a la promoción de la innovación, su difusión y transferencia), identificando, además, la relación dinámica entre protección, acceso y dominio público.

Lo anterior debe llevar al legislador no solo a establecer regulaciones para asegurar la debida protección de los derechos de PI (por ejemplo, mecanismos de cautela y tutela judicial efectiva), sino, también, normas que aseguren y promocionen la debida publicidad, difusión y transferencia tecnológica de los bienes protegidos por dichos derechos. Lo mismo vale para la administración, en materia de potestad reglamentaria. 
Esto tiene implicancias concretas. Así, el legislador deberá diseñar un esquema legal que asegure que los documentos que conforman una patente y que explican la solución tecnológica (esto es, memoria descriptiva, dibujos técnicos) permitan realmente replicar la innovación una vez que la patente expire y sea incorporada al dominio público ${ }^{110}$. Asimismo, dicho esquema deberá promover la publicación y difusión efectiva de dicho conocimiento, ya sea a cargo del INAPI, el Ministerio de Ciencia, Tecnología, Conocimiento e Innovación, o de Corfo, según corresponda de acuerdo con la naturaleza de la innovación en cuestión.

Asimismo, en consonancia con la norma constitucional propuesta, la ley y las normas administrativas deberían propender a instaurar mecanismos de promoción de transferencia tecnológica efectiva, ya sea desde entidades estatales ${ }^{111}$ con saberes tecnológicos (por ejemplo, Fuerzas Armadas) o centros de investigación (entre otras, universidades) a empresas, o desde empresas extranjeras a empresas nacionales. En este último punto la ley podría establecer ciertos requisitos en materia de inversión extranjera para asegurar el traspaso de conocimiento tecnológico a la industria local en el mediano o largo plazo, ya sea a través de políticas sofisticadas de disclosure, o promoviendo la celebración de licencias, o joint-ventures entre las entidades nacionales y las foráneas que sirvan de vehículo para la transferencia tecnológica formal entre ellas ${ }^{12}$.

\section{En materia de libre competencia}

Como es sabido, existen varios puntos de intersección entre el derecho de la libre competencia y la PI, tales como el abuso de posición dominante que podría originarse por la explotación de un derecho de PI (por ejemplo, denegación de acceso a patente incluida en un estándar técnico $)^{113} \mathrm{o}$

${ }^{110}$ Así, a modo de ilustración, en materia de patentes (en sentido amplio), a la fecha de redacción de este artículo, el INAPI ha publicado 121 "informes de tecnologías de domino público", disponibles en su sitio web.

${ }^{111}$ En estos casos se pueden instaurar licencias no exclusivas a favor del Estado para que este (y por su intermedio, la sociedad) pueda aprovechar una parte de las creaciones o innovaciones obtenidas por medio de su financiamiento. Así ocurre actualmente en materia de derechos de propiedad industrial originados con ocasión de proyectos financiados con recursos estatales, de acuerdo con el art. $9^{\circ}$ del decreto con fuerza de ley n. ${ }^{\circ} 33$ de 1981 .

${ }^{112}$ Pugatch (2005), p. 436.

${ }^{113}$ Estas son las denominadas patentes esenciales para la norma SEP o "PEN". A modo de ejemplo, el Tribunal de Justicia de la Unión Europea ha afirmado: "Habida cuenta del hecho de que el compromiso a conceder licencias en condiciones FRAND crea la expectativa legítima en terceros de que el titular de la PEN les conceda efectivamente licencias en esas condiciones, la negativa del titular de la PEN a conceder una licencia en tales condiciones 
la suscripción de acuerdos verticales u horizontales de cooperación que involucren licencias de derechos de PI y que tengan la aptitud de restringir la competencia.

La norma constitucional propuesta puede influir en estos casos a través del efecto horizontal de la $C P R$ y el deber de todo órgano jurisdiccional de interpretar la ley conforme a ella. Así, dado que la norma en cuestión esclarece la finalidad de la protección de la PI y su relación dinámica con la innovación y distribución del conocimiento, el Tribunal de Defensa de la Libre Competencia podrá asilarse en dichos conceptos para calibrar la interpretación del art. $3 .^{\circ}$ letras a) y b) del DL 211, en cada caso concreto.

Así, reconociendo que los titulares de derechos de PI requieren cierto grado de aislamiento del proceso competitivo para explotar eficazmente su innovación, se debe también admitir que este solo es legítimo en la medida en que sea compatible con los fines constitucionalmente asociados a la PI, a saber, contribuir a la innovación tecnológica y a su difusión en el largo plazo (i.e., eficiencia dinámica) ${ }^{114}$. Por supuesto, esto no quiere decir que mientras el derecho de PI se encuentre vigente el titular deba compartirlo, dado que dicha exigencia le privaría de las rentas schumpeterianas ya mencionadas. De lo que se trata, en cambio, es de que el titular no pueda instrumentalizar su derecho de PI para impedir la innovación 294 u obstaculizar el desarrollo tecnológico realizado por terceros fuera del ámbito de protección del derecho de $\mathrm{PI}^{115}$.

Así, la interpretación del art. $3 .^{\circ}$ letra b) del DL 211 debería ser adversa a que un agente con posición dominante utilice estratégicamente su derecho de PI, fuera del ámbito que le es propio, solo con el objetivo de prevenir la entrada de un producto no infractor al mercado ${ }^{116}$, pues dicho uso contravendría la finalidad constitucionalmente declarada de su derecho. Asimismo, tampoco podrían aceptarse conductas oportunistas que consistan en el registro de patentes o marcas comerciales sin la intención de explotarlas, sino que con el solo fin de bloquear la entrada u operaciones comerciales de un potencial competidor.

puede constituir, en principio, un abuso en el sentido del artículo 102 TFUE”. Caso Huawei Technologies Co. Ltd. v. ZTE Corp. y ZTE Deutschland GmbH (2015), párrafo 53.

${ }^{114}$ Para un análisis más detallado de la relación de la PI con la libre competencia, desde un punto de vista de eficiencia dinámica, véase Iglesias y Programa de Libre ComPETENCIA UC (2021).

${ }^{115}$ Esto especialmente considerando que los derechos de PI contemplan mecanismos internos de acceso (véase nota al pie n. ${ }^{\text { }}$ 84). Para una revisión de la forma en que los mecanismos internos de acceso establecidas en la misma regulación de la PI, véase IGLESIAS y Programa de Libre Competencia UC (2021), pp. 10-12.

${ }^{116}$ En este sentido, véase sentencia en Microsoft v. Comisión Europea (2007), párrafo 643 y ss. 
Bajo la misma lógica, la interpretación del art. $3 .^{\circ}$ letra a) del DL 211 debería ser en principio favorable a que dos agentes de mercado puedan celebrar acuerdos de colaboración o joint-ventures en materia de investigación y desarrollo, o en materia de transferencia tecnológica (a saber: licencias cruzadas o consorcios tecnológicos) orientados a desarrollar nuevos productos o mejorar los ya existentes ${ }^{117}$. Lo anterior, en la medida en que se cumplan ciertas condiciones como, por ejemplo, que los derechos de PI involucrados no sean sustitutos entre sí ${ }^{118}$, sino mutuamente "bloqueadores" o, a lo menos, complementarios ${ }^{119}$.

\section{En materias de competencia civil ordinaria}

Por último, en materia de justicia ordinaria, es decir, casos de infracción civil de derechos de PI, ya sea bajo la Ley n. ${ }^{\circ} 19039$ o la Ley n. ${ }^{\circ} 17336$, la norma constitucional propuesta influenciará la interpretación de todos los conceptos jurídicos que tengan una "textura abierta", siendo particularmente relevantes aquellos que se relacionen con los usos de tecnologías o

${ }^{117}$ La ausencia de colaboración entre competidores en materia de innovación en Chile fue identificado por la OCDE como un obstáculo significativo al flujo de conocimiento entre empresas ("The majority of Chilean firms do not perceive the value of co-operation in innovation, and those that do not find institutional frameworks that facilitate marketfriendly forms of collective action"). OCDE (2007) p. 13. (Traducción libre: "La mayoría de las empresas chilenas no perciben el valor de la cooperación en la innovación, y las que no encuentran marcos institucionales que faciliten formas de acción colectiva amigables con el mercado"). En este sentido, hace falta una regulación legal o, al menos, una guía normativa de la Fiscalía Nacional Económica sobre colaboración empresarial compatible con la libre competencia, a lo menos respecto a los acuerdos proinnovación. Así lo ha hecho Estados Unidos, estableciendo puertos seguros y criterios transparentes para evaluar acuerdos de investigación y desarrollo, a través de las "Directrices Antimonopolio para la Colaboración entre Competidores" (sección 3.31-a) y las "Directrices Antimonopolio para el Licenciamiento de Derechos de Propiedad Intelectual" (sección 4.3), ambas elaboradas por el Departamento de Justicia y la Comisión Federal de Comercio de Estados Unidos, en los años 2000 y 2017, respectivamente. Así también lo ha hecho la Unión Europea, mediante la "Comunicación Fijando las Directrices sobre la Aplicabilidad del Art. 101 párrafo $3^{\circ}$ del Tratado de Funcionamiento de la Unión Europea a los Acuerdos de Cooperación Horizontal" (sección 3) y el reglamento n. ${ }^{\circ}$ 1217/2010 sobre determinadas categorías de acuerdos de investigación y desarrollo, ambos dictados por la Comisión Europea, en los años 2011 y 2010, respectivamente (entre otros instrumentos normativos afines).

${ }^{118} \mathrm{Al}$ respecto, las directrices de la Unión Europea relativas a la aplicación del art. 101 del Tratado de Funcionamiento de la Unión Europea a los acuerdos de transferencia de tecnología señalan: "La inclusión en un consorcio de tecnologías sustitutivas restringe la competencia inter-tecnologías, ya que puede equivaler a una agrupación colectiva y dar lugar a la fijación de precios entre competidores" (párrafo 255).

${ }^{119}$ Carlson (1999), pp. 362-365. 
creaciones artísticas exentas del régimen de autorización. En efecto, estos usos están implícitamente inscritos en la norma constitucional propuesta, ya que tienen relación directa con la finalidad de promover la creación y la difusión del conocimiento ${ }^{120}$.

De este modo, la norma constitucional propuesta reforzará los actuales regímenes de excepciones de autorización, además de los nuevos que pueda establecer el legislador, en la medida en que estos se ajusten a las finalidades constitucionalmente declaradas de la PI.

\section{CONCLUSIÓN}

"La tierra es de quien la trabaja", rezaba el lema de la revolución zapatista en México a principios del siglo xx. El objetivo de este artículo ha sido proponer una norma constitucional que, de manera análoga, permita que la PI sea entendida como una asignación de (una especie de) propiedad para quien crea o innova y que, además, contribuye a incrementar, en el mediano o largo plazo, la acumulación de conocimiento tecnológico y artístico disponible para la sociedad en su conjunto.

Es ciertamente sintomático que en la historia fidedigna del actual art.

29619 n. ${ }^{\circ} 25$ de la $C P R$ no se mencione la palabra 'innovación'. Ello revela que dicha norma debe ser actualizada a las necesidades del siglo XXI y la discusión constitucional que se está llevando a cabo en Chile es una buena oportunidad para reflexionar sobre la PI desde los objetivos que le son propios. Para ello es imprescindible separar con claridad la protección constitucional de la propiedad tradicional, que supone bienes ya existentes y escasos, de la PI, que supone bienes en principio no existentes y que, una vez creados, tienen el carácter de "público" (es decir, no-rivales y no-excluibles).

La norma constitucional propuesta en este artículo tiene por objetivo ofrecer un marco constitucional para que el resto de la pirámide normativa del ordenamiento jurídico tenga por desafío permanente utilizar la PI con miras a, de manera progresiva, optimizar la creación y el acceso al conocimiento en la sociedad. Lo anterior supone estructurar la PI de manera tal que cumpla el principio de la diferencia rawlsiano, es decir, que pueda ser comprendida como una institución que, a mediano o largo plazo, beneficia a todos los miembros de la sociedad, especialmente a los más desventajados.

Por último, es esperable que la norma propuesta, a pesar de tener un papel programático, induzca efectos concretos en el ámbito legislativo,

${ }^{120}$ Véase nota al pie n. ${ }^{\circ} 84$. 
administrativo y judicial, tanto en procedimientos de registro de derechos, procedimientos civiles ordinarios y procedimientos de libre competencia, entre otros.

\section{Bibliografía CITADA}

Arrow, Kenneth (1962). "Economic Welfare and the Allocation of Resources for Invention", in National Bureau of Economic Research. The Rate and Direction of Inventive Activity, Economic and Social Factors. Princeton: Princeton University Press.

Baker, Dean, Arjun Jayadev \& Joseph Stiglitz (2017). Innovation, Intellectual Property, and Development: A better set of approaches for the $27^{\text {st }}$ century. Proyecto de Shuttleworth Foundation. Disponible en http://ip-unit.org/wp-content/ uploads/2017/07/IP-for-21st-Century-EN.pdf [fecha de consulta: 2 de julio de 2021].

BARCELÓ, Joaquín (1993). "Acerca del fundamento del derecho de propiedad". Revista Estudios Públicos, n. ${ }^{\circ}$ 52. Santiago, primavera.

Barros Bourie, Enrique (2021). "Por qué proteger constitucionalmente la propiedad", en Departamento de Derecho Privado, Facultad de Derecho Universidad de Chile. Derecho civil y Constitución. Valencia: Tirant lo Blanch.

BLAIR, Roger \& Wenche WANG (2017). "Monopoly Power and Intellectual Property", in Roger BlaIR \& Daniel SoKol (eds.) The Cambridge Handbook of Antitrust, Intellectual Property, and High Tech. Cambridge: Cambridge University Press

Brian, Arthur (2009). The Nature of Technology, What it is and how it evolves. New York: Free Press.

CARLson, Steven C. (1999). "Patent Pools and the Antitrust Dilemma". Yale Journal on Regulation, vol. 16. New Haven.

Chang, Ha-Joon (2008). Bad Samaritans, The Guilty Secrets of Rich Nations and the Threat to Global Prosperity. London: Random House Business Books.

Consejo Nacional de Ciencia, Tecnología, Conocimiento e Innovación para el Desarrollo (2021). Base para la estrategia nacional CTCI 2021. Disponible en www.cnid.cl/portfolio-items/base-para-la-estrategia-nacional-de-cienciatecnologia-conocimiento-e-innovacion [fecha de consulta: 2 de julio 2021].

Cordua, Carla (1994). "Selección de textos políticos de Hegel”. Revista de Estudios Públicos, n. ${ }^{\circ}$ 54. Santiago.

Cortés Rosso, Mauricio (2012). Patentes de invención, aspectos jurídicos. Santiago: Editorial Thomson Reuters.

DaGan, Hanoch (2011). Property: Values and Institutions. Oxford: Oxford University Press.

De La Maza Gazmuri, Iñigo (2006). "Propiedad intelectual, teorías y alternativas, en Marcos Morales Andrade (coord.). Temas actuales de la propiedad intelec- 
tual: estudios en homenaje a la memoria del profesor Santiago Larraguibel Zavala. Santiago: Lexis Nexis.

Department of Justice \& Federal Trade Commission (2000). "Antitrust Guidelines for Collaboration Among Competitors". Disponible en www.ftc.gov/ sites/default/files/documents/public_events/joint-venture-hearings-antitrustguidelines-collaboration-among-competitors/ftcdojguidelines-2.pdf [fecha de consulta: 21 de agosto 2021].

Department of Justice \& Federal Trade Commission (2017). "Antitrust Guidelines for the Licensing of Intellectual Property Rights". Disponible en www.ftc. gov/system/files/documents/public_statements/1049793/ip_guidelines_2017. pdf [fecha de consulta: 2 de julio 2021].

Domínguez ÁGuila, Ramón (1996). "Aspectos de la constitucionalización del derecho civil chileno". Revista de Derecho y Jurisprudencia, tomo XCII, n. ${ }^{\circ}$ 3. Santiago.

Dreyfuss, Rochelle (1990). "Expressive Generecity: Trademarks as Language in the Pepsi Generation". Notre Dame Law Review, vol. 65, issue 3. Indiana.

Grosse Ruse-Khan, Henning (2018). "From TRIPS to FTAs and Back: ReConceptualising the Role of a Multilateral IP Framework in a TRIPS-Plus World”. Max Planck Institute for Innovation and Competition Research Paper, No. 18-02. Cambridge.

GuZmán BRito, Alejandro (2006). Las cosas incorporales en la doctrina y en el derecho positivo. $2^{\mathrm{a}}$ ed. actualizada. Santiago: Editorial Jurídica de Chile.

Haber, Stephen (2016). "Patents and the Wealth of Nations". George Mason Law Review, vol. 23, No. 4. Virginia.

Harding, Garret (1968). "The Tragedy of Commons". Science, vol. 162. (trad.) Horacio Bonfil Sánchez. Gaceta Ecológica, núm. 37. México: Instituto Nacional de Ecología, 1995.

HaYeK, Friedrich A. (1948). Individualism and Economic Order. Chicago: The University of Chicago Press.

Hayek, Friedrich A. (1960). The Constitution of Liberty. London: Routledge.

JaCKson, Giorgio y Paula EsPinOza (2019). Copia o muerte. Una decisión urgente para nuestra supervivencia. Saber Futuro. Disponible en http://copiaomuerte. org [fecha de consulta: 2 de julio 2021].

Iglesias Mujica, Juan Pablo y Programa de Libre Competencia UC (2021). "Intersección entre la Libre Competencia y la Propiedad Intelectual: Análisis Dinámico e Inmunidad Relativa”. Antitrust Position Papers, n. ${ }^{\circ}$. Documento elaborado en el Programa de Libre Competencia UC. Disponible en https:// librecompetencia.uc.cl/images/AAA/APP/APP_5_1.pdf [fecha de consulta: 20 de agosto 2021].

Katz, Ariel. (2007). "Making Sense of Nonsense: Intellectual Property, Antitrust, and Market Power". Arizona Law Review, vol. 49, issue 4. Arizona.

Landes, William M. \& Richard Posner (1987). “Trademark Law: An Economic Perspective". The Journal of Law \& Economics, vol. 30, issue 2. Chicago. 
Landes, William M, \& Richard Posner (1989). "An Economic Analysis of Copyright Law”. The Journal of Legal Studies, vol. 18, No. 2. Chicago.

LiAnos, Ioannis (2010). "Las implicancias de una teoría regulatoria de la Propiedad Intelectual (PI) para el Derecho de la Libre Competencia: visión desde Europa". Revista de Derecho Económico, n. ${ }^{\circ} 75$. Santiago.

Lianos, Ioannis \& Rochelle Dreyfuss (2013). "New challenges in the intersection of Intellectual Property Rights with Competition Law, a view from Europe and the United States". CLES Research Paper series 4/2013. London.

Liscomb, Andrew \& Albert Ellery (eds.) (1905). The Writings of Thomas Jefferson, Washington DC: Thomas Jefferson Memorial Association.

Liu, Deming (2012). "Copyright and the Pursuit of Justice: a Rawlsian Analysis". Legals Studies, vol. 32, No. 4. Oxford, December.

Lypszyc, Delia (1993). Derecho de autor y derechos conexos. Buenos Aires: Editorial UNESCO.

Marshall Barberán, Pablo (2010). "El efecto horizontal de los derechos y la competencia del juez para aplicar la Constitución”. Estudios Constitucionales, año 8 , n. ${ }^{\circ}$ 1. Santiago.

Mazzuchto, Mariana (2013). The Entrepreneurial State. New York: Public Affairs.

MotтA, Massimo (2009). Competition Policy, Theory and Practice. $12^{\text {th }}$ ed. Cambridge: Cambridge University Press.

MurPhy, Darryl (2012). "Are Intellectual Property Rights Compatible with Rawlsian Principles of Justice?”. Ethics and Information Technology, vol. 14, issue 2. London.

NozIck, Robert (1974). Anarchy, State, and Utopia. Oxford: Basil Blackwell.

OCDE (2007). Reviews of Innovation Policy, Chile. Disponible en www.oecd.org/sti/ inno/oecdreviewsofinnovationpolicychile.htm [fecha de consulta: 2 de julio 2021].

PARK, Walter G. \& Douglas C. LiPPOLDT (2008). "Technology Transfer and the Economic Implications of the Strengthening of Intellectual Property Rights in Developing Countries". OECD Trade Policy Working Paper, No. 62, OECD Publishing. Disponible en www.oecd-ilibrary.org/trade/technology-transfer-andthe-economic-implications-of-the-strengthening-of-intellectual-property-rightsin-developing-countries_244764462745 [fecha de consulta: 20 de agosto 2021].

Petit, Nicolas \& David Teece (2021). "Innovating Big Tech Firms and Competition Policy: Favoring Dynamic Over Static Competition”. Working paper. Disponible en SSRN https://papers.ssrn.com/sol3/papers.cfm?abstract_id=3229180 [fecha de consulta: 20 de agosto 2021].

Pizarro Wilson, Carlos (2006). “Comentarios de jurisprudencia. Daño moral a las personas jurídicas". Revista Chilena de Derecho Privado, n. ${ }^{\circ}$ 6. Santiago.

Pugatch, Meir (2005). "The International Regulation of IPRs in a TRIPS and TRIPS-plus World". The Journal of World Investment \& Trade, vol. 6, issue 3. Leiden.

RADIN, Margaret Jane (2004). "Regime Change in Intellectual Property: Superseding the Law of the State with the 'Law' of the Firm". University of Ottawa Law \& Technology Journal, vol. 1. Ottawa. 
Rawls, John (1971). Teoría de la justicia. (trad.) María Dolores GonZÁlez. Ciudad de México: Fondo de Cultura Económica.

Schumpeter, Joseph (2012). Capitalism, Socialism and Democracy. Hoboken, New Jersey: Start Publishing LLC, Kindle eBook.

SHIfFrin, Seana (2001). "Lockean Arguments for Private Intellectual Property",in Stephen Munzer (ed.). New Essays in the Legal and Political Theory of Property. Cambridge: Cambridge University Press.

STRAus, Joseph (2007). "The Impact of the New World Order on Economic Development: The Role of the Intellectual Property Rights System”. European Review, vol. 15, No. 1. Cambridge.

Teece, David, J (1986). "Profiting from technological innovation: Implications for integration, collaboration, licensing and public policy". Research policy, vol. 15, issue 6. North-Holland.

Ubilla FuenZalida, Jaime (2016). "El derecho real de conservación, justificación normativa y sociolegal”. Revista de Derecho, n. ${ }^{\circ} 240$, año LXXXIV. Concepción.

VARGas WeIL, Ernesto (2021). "Las bases privatistas de la propiedad constitucional: una aproximación comparada", en Departamento de Derecho Privado, Facultad de Derecho, Universidad de Chile. Derecho civil y Constitución. Valencia: Tirant lo Blanch.

WALDRON, Jeremy (1992). "From Authors to Copiers: Individual Rights and Social Values in Intellectual Property". Chicago-Kent Law Review. vol. 68, issue 2, Chicago.

Yamane, Hiroko (2011). Interpreting TRIPS: Globalisation of Intellectual Property Rights and Access to Medicines. Oxford: Hart Publishing.

\section{Jurisprudencia citada}

Codelco con A. (2014): Tribunal Constitucional, causa rol n. ${ }^{\circ}$ 2365-12-INA, 14 de enero de 2014.

Google LLC v. Oracle America, Inc. (2021): Corte Suprema de Estados Unidos, 593 U. S. 5 de abril de 2021.

Huawei Technologies Co. Ltd. v. ZTE Corp. y ZTE Deutschland GmbH (2015): Tribunal de Justicia de la Unión Europea, C-170/13, ECLI:EU:C:2015:477, 16 de julio de 2015.

Microsoft Corp. v. Comisión Europea (2007): Tribunal de Primera Instancia (Gran Sala) de la Unión Europea, T201/04, ECLI:EU:T:2007:289, 17 de septiembre de 2007.

Ruckelshaus v. Monsanto Co. (1984): Corte Suprema de Estados Unidos, 467 U.S. 986, 1001-04, 26 de junio de 1984. 


\section{Normas citadas}

Constitución Política de la República.

Código Civil.

Ley n. ${ }^{\circ}$ 19039, Establece Normas Aplicables a los Privilegios Industriales y Protección de los Derechos de Propiedad Industrial, en Diario Oficial de la República de Chile, Santiago, 25 de enero de 1991.

Ley n. ${ }^{\circ}$ 17336, sobre Propiedad Intelectual, en Diario Oficial de la República de Chile, Santiago, 2 de octubre de 1970.

Ley n. ${ }^{\circ} 19342$, Regula Derechos de Obtentores de Nuevas Variedades Vegetales, en Diario Oficial de la República de Chile, Santiago, 3 de noviembre de 1994.

Ley n. ${ }^{\circ} 21355$, Modifica la Ley n. ${ }^{\circ} 19039$, de Propiedad Industrial y la Ley n. ${ }^{\circ} 20254$, que establece el Instituto Nacional de Propiedad Industrial, en Diario Oficial de la República de Chile, Santiago, 5 de julio de 2021.

Decreto ley n. ${ }^{\circ}$ 211, Fija Normas para la Defensa de la Libre Competencia, en Diario Oficial de la República de Chile, Santiago, 22 de diciembre de 1973.

Decreto con fuerza de ley n. ${ }^{\circ} 33$ de 1981, que crea el Fondo Nacional de Desarrollo Científico y Tecnológico y Fija Normas de Financiamiento de la Investigación Científica y Tecnológica, en Diario Oficial de la República de Chile, Santiago, 27 de octubre de 1981.

SigLAS Y ABREVIATURAS

ADPIC Acuerdo sobre los Aspectos de los Derechos de Propiedad Intelectual Relacionados con el Comercio

art. artículo

arts. artículos

Codelco Corporación Nacional del Cobre

Corfo Corporación de Fomento de la Producción

Corp. Corporation

CTICI Consejo Nacional de Ciencia, Tecnología, Conocimiento e Innovación para el Desarrollo

cons. considerando

coord. coordinador

CPR Constitución Política de la República

DC District of Columbia

DL decreto ley

ed. edición a veces editor 
eds. editores

GATT General Agreement on Tariffs and Trade (Acuerdo General sobre Aranceles Aduaneros y Comercio)

http HyperText Transfer Protocol

https HyperText Transfer Protocol Secure

Ibid. Ibidem (allí, en ese mismo lugar)

i.e. id est (esto es)

INAPI Instituto Nacional de Propiedad Industrial

Inc. Incorporated

LL.M Legum Magister

Ltd. Limited

n. ${ }^{\circ}$ a veces núm, No. número

OCDE Organización para la Cooperación y el Desarrollo Económico

op. cit. opere citato (obra citada)

p. página

PI Propiedad Intelectual (derechos de autor, la propiedad industrial y las

302 variedades vegetales)

pp. páginas

Pymes pequeñas y medianas empresas

SEP. Standard Essential Patents

ss. siguientes

trad. traducción

UNESCO United Nations Educational, Scientific and Cultural Organization

v. versus

vol. volumen

vr. gr. verbi gratia (por ejemplo) 